\title{
Dystrophin Dp71 and the Neuropathophysiology of Duchenne Muscular Dystrophy
}

\author{
Michael Naidoo $^{1} \cdot$ Karen Anthony $^{1}$ (D) \\ Received: 1 October 2019 / Accepted: 22 November 2019 / Published online: 13 December 2019 \\ (C) The Author(s) 2019
}

\begin{abstract}
Duchenne muscular dystrophy (DMD) is caused by frameshift mutations in the DMD gene that prevent the body-wide translation of its protein product, dystrophin. Besides a severe muscle phenotype, cognitive impairment and neuropsychiatric symptoms are prevalent. Dystrophin protein 71 (Dp71) is the major DMD gene product expressed in the brain and mutations affecting its expression are associated with the DMD neuropsychiatric syndrome. As with dystrophin in muscle, Dp71 localises to dystrophinassociated protein complexes in the brain. However, unlike in skeletal muscle; in the brain, Dp71 is alternatively spliced to produce many isoforms with differential subcellular localisations and diverse cellular functions. These include neuronal differentiation, adhesion, cell division and excitatory synapse organisation as well as nuclear functions such as nuclear scaffolding and DNA repair. In this review, we first describe brain involvement in DMD and the abnormalities observed in the DMD brain. We then review the gene expression, RNA processing and functions of Dp71. We review genotype-phenotype correlations and discuss emerging cellular/tissue evidence for the involvement of Dp71 in the neuropathophysiology of DMD. The literature suggests changes observed in the DMD brain are neurodevelopmental in origin and that their risk and severity is associated with a cumulative loss of distal DMD gene products such as Dp71. The high risk of neuropsychiatric syndromes in Duchenne patients warrants early intervention to achieve the best possible quality of life. Unravelling the function and pathophysiological significance of dystrophin in the brain has become a high research priority to inform the development of brain-targeting treatments for Duchenne.
\end{abstract}

Keywords Duchenne muscular dystrophy $\cdot$ Dystrophin $\cdot$ Dp71 $\cdot$ Apo-dystrophin- $1 \cdot$ Neurodevelopment

\section{Introduction}

The X-linked neuromuscular disorder, Duchenne muscular dystrophy (DMD), is one of the most common fatal genetic disorders diagnosed in childhood. It is caused by frameshift mutations in the DMD gene that prevent the body-wide translation of its protein product, dystrophin. Although characterised by the progressive loss of muscle strength and function [1], cognitive impairment and neuropsychiatric symptoms are also prevalent. Mounting evidence links these symptoms to the loss of dystrophin in the brain.

Karen Anthony

karen.anthony@northampton.ac.uk

1 Centre for Physical Activity and Life Sciences, Faculty of Arts, Science and Technology, University of Northampton, University Drive, Northampton, Northamptonshire NN1 5PH, UK
Unlike skeletal muscle, the central nervous system (CNS) sees the expression of a large variety of $D M D$ transcripts implicated in diverse cellular processes [2]. Dystrophin protein variants (Dp) are named based on their length in kilodaltons and are produced through unique promoter usage, alternative splicing and/or alternative polyadenylation signals. The most predominant in the brain is the Dp71 variant expressed in neurones and glia, except during foetal development where Dp140, also expressed throughout the CNS, dominates [3, 4]. Distal DMD mutations affecting the expression of these shorter variants are linked to cognitive impairment [5-11]. Dp140 and Dp71 are both heavily implicated. The risk and severity of cognitive disability are associated with a cumulative loss of distal $D M D$ gene products $[5,12]$. Thus, it is not entirely clear which, if any, single $D M D$ gene product is responsible for the CNS phenotype. There is limited information on Dp140, likely due to its restricted expression pattern. In contrast, our knowledge of Dp71 has expanded rapidly, there are mouse models devoid of Dp71 and the literature has become complex. In light 
of this and the fact that $100 \%$ of individuals with mutations affecting Dp71 have intellectual disability [5, 6, 8, 9, 11], we limit the focus of this review to Dp71.

As many as 14 isoforms of Dp71 have now been described (Fig. 1) and our understanding of the function(s) of Dp71 has increased. Here, we provide a detailed update on Dp71 and review the accumulating evidence linking its loss to the neuropathophysiology of Duchenne. We first describe the 'DMD neuropsychiatric syndrome' coined by Ricotti [13] and the abnormalities observed in the DMD brain. We then review the gene expression and RNA processing of Dp71 and its function(s) and discuss how the absence and/or alteration of Dp71 likely contributes to the neuropathophysiology of DMD.

\section{The Duchenne Brain: Human and Animal Models}

\section{Emotional, Behavioural and Neurodevelopmental Observations}

Whilst most individuals with DMD are not intellectually disabled, the risk of cognitive impairment is higher than for the general population. Full-scale intelligent quotients (FSIQ) are consistently reported at one standard deviation below the normal population mean $[13,14]$ and levels of intellectual disability within Duchenne cohorts vary between approximately 19 and 35\% (Table 1, [13-15]). Patients with distal DMD mutations affecting the expression of all $D M D$ gene products have lower FSIQ scores than those with mutations that result
Table 1 Neurological comorbidities in DMD patients

\begin{tabular}{lcl}
\hline Comorbidity & Approximate prevalence (\%) & Reference(s) \\
\hline Intellectual disability & $19-35$ & {$[14-16]$} \\
Epilepsy & $2-12$ & {$[17-20]$} \\
Autism & 20 & {$[13,21-23]$} \\
Internalising problems & $24-34$ & {$[13,16]$} \\
Depression & $17-27$ & {$[24-26]$} \\
Anxiety & $24-29$ & {$[16,25-27]$} \\
OCD & $5-14$ & {$[16,27,28]$} \\
Externalising problems & 15 & {$[13]$} \\
ADHD & $12-32$ & {$[10,13,28]$} \\
Reading disability & $40-50$ & {$[29-32]$} \\
\hline
\end{tabular}

in only the absence of full-length dystrophin [5]. Patients lacking Dp140 and/or Dp71 have a particularly high incidence of neurodevelopmental disorders [13]. There is a reported increase in epilepsy in patients with Duchenne compared with the general population (Table 1) and other brain-related comorbidities such as attention deficit hyperactivity disorder (ADHD) and obsessive compulsive disorder (OCD) are more prevalent in patients who have both DMD and epilepsy compared with non-epilepsy Duchenne patients [17]. Internalising disorders are reported in around a third of patients [13, 16] with depression, anxiety and OCD all having a higher prevalence than for the general paediatric population (Table 1). Externalising problems have been reported through parent reports in $15 \%$ of DMD patients [13], and other studies reveal a diagnosis of ADHD in up to $32 \%$ of DMD cohorts $[10,13,28]$.
Fig. 1 Dp71 isoforms and preferred nomenclature. Dp71 splice isoforms are grouped according to their C-terminus. The d group contain exons 78 and 79 , the f group lacks exon 78 and has an alternative exon 79 (79f), the e group contains part of intron 77 (i77) and lacks exons 78 and 79 and the g group isoform has a stop codon in exon 77. Their differential C-termini are illustrated and the location of dystroglycan and syntrophin-binding sites are indicated

\begin{tabular}{|c|c|c|c|c|c|c|c|c|c|c|c|c|c|c|c|c|c|c|}
\hline Gro & oup d & & Dystroc & glycan & -bindin & ing site & & & & Syntr & ophin- & -bindi & ing site & & & & & \\
\hline 1 & 63 & 64 & 65 & 66 & 67 & 68 & 69 & 70 & 71 & 72 & 73 & 74 & 75 & 76 & 77 & 78 & 79 & Dp71d \\
\hline 1 & 63 & 64 & 65 & 66 & 67 & 68 & 69 & 70 & & 72 & 73 & 74 & 75 & 76 & 77 & 78 & 79 & $\mathrm{Dp} 71 \mathrm{~d}_{\Delta 71}$ \\
\hline 1 & 63 & 64 & 65 & 66 & 67 & 68 & 69 & 70 & 71 & 72 & 73 & & 75 & 76 & 77 & 78 & 79 & Dp71d $_{\Delta 74}$ \\
\hline 1 & 63 & 64 & 65 & 66 & 67 & 68 & 69 & 70 & & 72 & 73 & & 75 & 76 & 77 & 78 & 79 & $\mathrm{Dp} 71 \mathrm{~d}_{\Delta 71,74}$ \\
\hline 1 & 63 & 64 & 65 & 66 & 67 & 68 & 69 & 70 & & 72 & & & 75 & 76 & 77 & 78 & 79 & $\mathrm{Dp} 1 \mathrm{~d}_{\Delta 71,73-74}$ \\
\hline 1 & 63 & 64 & 65 & 66 & 67 & 68 & 69 & 70 & & & & & 75 & 76 & 77 & 78 & 79 & Dp71d $_{\Delta 71-74}$ \\
\hline Gro & up $f$ & & & & & & & & & & & & & & & & & \\
\hline 1 & 63 & 64 & 65 & 66 & 67 & 68 & 69 & 70 & 71 & 72 & 73 & 74 & 75 & 76 & 77 & & 791 & Dp71f \\
\hline 1 & 63 & 64 & 65 & 66 & 67 & 68 & 69 & 70 & & 72 & 73 & 74 & 75 & 76 & 77 & & $79 f$ & ${\mathrm{Dp} 71 f_{\Delta 71}}$ \\
\hline \begin{tabular}{|l|}
1 \\
\end{tabular} & 63 & 64 & 65 & 66 & 67 & 68 & 69 & 70 & & 72 & & 74 & 75 & 76 & 77 & & 796 & Dp71f $_{\Delta 71,73}$ \\
\hline 1 & 63 & 64 & 65 & 66 & 67 & 68 & 69 & 70 & 71 & 72 & 73 & & 75 & 76 & 77 & & 791 & $\mathrm{Dp} 1 \mathrm{f}_{\Delta 74}$ \\
\hline 1 & 63 & 64 & 65 & 66 & 67 & 68 & 69 & 70 & & & & & 75 & 76 & 77 & & $79 f$ & Dp71f $_{\Delta 71-74}$ \\
\hline & up e & & & & & & & & & & & & & & & & & \\
\hline 1 & 63 & 64 & 65 & 66 & 67 & 68 & 69 & 70 & & 72 & 73 & 74 & 75 & 76 & 77 & $i 77$ & & Dp71e $_{\Delta 71}$ \\
\hline 1 & 63 & 64 & 65 & 66 & 67 & 68 & 69 & 70 & & & & & 75 & 76 & 77 & $i 77$ & & $\mathrm{Dp} 71 \mathrm{e}_{\Delta 71-74}$ \\
\hline & up g & & $\sqrt{65}$ & & & & & & & & & & & & & & & \\
\hline 1 & 63 & 64 & 65 & 66 & 67 & & & & & & & & & & 77 & & & ${ }^{D p 71} g_{\triangle 68-76}$ \\
\hline
\end{tabular}


In addition to the comorbidities listed in Table 1, memory deficits are widely acknowledged with impairments in shortterm working memory particularly apparent (e.g. story recall, digit span and auditory comprehension) [33-38]. Together with a high occurrence of reading disabilities $(40-50 \%$, Table 1) and speech delay [39], these deficits likely affect academic achievement. In the study by Ricotti [13], over a third of boys presented with at least two neurological comorbidities and Battini et al. [34] show that cognitive impairment is apparent even in patients without intellectual disability. Individuals with the similarly progressive disorder, spinal muscular atrophy, do not show the reading and learning disabilities described for DMD suggesting that cognitive impairment in DMD does not depend on motor disability [40]. The breadth and clustering of behavioural and neurodevelopmental disorders in DMD reveal the existence of a 'DMD neuropsychiatric syndrome' [13] which warrants prompt management and therapeutic intervention.

\section{Animal Models}

It is unlikely that animal models can fully recapitulate the DMD neuropsychiatric syndrome, although alterations in learning and behaviour are apparent. The most commonly used DMD disease model is the $m d x$ mouse which harbours a naturally occurring nonsense mutation in $d m d$ exon 23 resulting in an absence of full-length dystrophin expression [41]. Fear-motivated defensive behaviour, and according to some studies anxiety, are enhanced in $m d x$ mice [42, 43]. Altered social behaviour and ultrasonic communication are noted [44] and learning and memory performance is impaired in some studies [45-49] but not others [50,51]. Other $m d x$ strains have been developed to explore the contribution of the different $D M D$ gene products to pathology and disease phenotype. The $m d x 3 c v$ mouse retains a low level of expression of near full-length dystrophin but is deficient in C-terminal dystrophin gene products [52]; Im et al. [53] show this to be the only $m d x$ strain without Dp71 expression in the brain. The $m d x 3 c v$ mice display enhanced anxiety-related behaviour and reduced locomotion in comparison with $m d x$, although surprisingly learning impairments are subtle and in some tests on par with $m d x$ [54]. Dp71-null mice have been developed by homologous recombination; in contrast to $m d x$ strains, they do not display muscular dystrophy [55]. These mice have deficits in cognitive flexibility, spatial learning and memory and cerebellum-dependent navigation strategies [56, 57]. Results from the Daoud et al.'s study [58] suggest that the learning deficits in Dp71-null mice are more severe than $m d x$. Reports of cognitive deficiency in any dog or large DMD animal models are scarce. In dystrophin-deficient miniature poodles, learning difficulties and abnormal behaviours have been reported, these dogs have a large deletion on the $\mathrm{X}$ chromosome encompassing the entire DMD gene [59].

\section{Gross Anatomical and Histological Observations}

There is conflicting evidence relating to the presence and extent of anatomical brain abnormalities in DMD. Many studies report no gross central nervous system disturbances [60-63]. Other work describes both gross and histological abnormalities in DMD patients with varying degrees of severity [64-67]. Jagadha and Becker [66] report several neuropathological observations including neuronal loss, gliosis, Purkinje cell loss and abnormal dendritic development. One autopsy report of a DMD individual with severe intellectual disability revealed an atrophic brain with unusual multifocal small nodules in multiple layers of the prefrontal cortex [67]. The nodules were of astrocytic origin and believed to be a result of changes during early brain development. Other studies have also reported brain atrophy amongst DMD cohorts [68, 69]. Yoshioka et al. [68] observed slight cerebral atrophy in $67 \%$ of DMD patients and found that severity correlated with age. This is suggestive of a progressive cerebral degeneration, although there have been no longitudinal studies to confirm if the behavioural and cognitive symptoms themselves are progressive.

The head circumference of boys with Duchenne is larger than the normal population indicative of macrocephaly [70, 71]. Although the majority of DMD patients with relative, or absolute, macrocephaly are intellectually impaired, head circumference does not correlate with intellectual performance in DMD [70]. Interestingly, in Alzheimer's disease patients with cerebral atrophy, a larger head circumference is associated with less cognitive impairment [72]. To some extent, the larger head circumference in DMD may be determined by hypertrophy of temporal muscles, skull shape is also significantly rounder in DMD patients compared with controls [73]. Conversely, no differences are found in skull morphology of $m d x$ mice, presumably since bite force is unaffected in these mice $[74,75]$.

Electrophysiological studies using electroencephalograms (EEG) on DMD patients have been reviewed in 2002 [63], most studies report a higher proportion of abnormalities amongst DMD patient groups. A transcranial magnetic stimulation study showed reduced excitability of the motor cortex attributed to altered synaptic functioning and reduced dystrophin at the synapse [76].

An MRI study by Doorenweerd et al. [12] confirms the consensus that upon routine assessment, the brains of individuals with DMD (and animal models) show no gross abnormalities. Detailed quantitative analysis of images from an increased sample size did however reveal significantly smaller total brain and grey matter volumes in a DMD patient group. Further analysis showed significantly smaller grey matter regions in the left insula and occipital lobe, but these regions are too small to account for the reduced volume alone. White matter fractional anisotropy was also lower and radial diffusivity higher in DMD patients 
versus controls indicating that while white matter volume is unaffected, its structural organisation is compromised [12]. Smaller grey matter volume has been reported elsewhere [77] and Doorenweerd et al. suggest that, after correcting total brain volume to intracranial volume, altered brain maturation is responsible for smaller Duchenne brains rather than atrophy [12]. These alterations were more pronounced in patients lacking Dp140, patients lacking Dp71 were unavailable to this study. Independently of grey matter volume, cerebral blood flow (CBF) is lower (17\%) in DMD patients compared with controls with no correlation to age, ambulation or cardiac involvement [12], $\mathrm{CBF}$ is also reduced to the same extent in the $m d x$ mouse [78].

MRI studies in $m d x$ mice have shown no significant differences in total brain volumes $[75,79,80]$, although regional structural changes are apparent with reports of enlarged lateral ventricles [80], hippocampus, globus pallidus and caudate putamen and a smaller hypothalamus [75].

\section{Molecular Pathophysiology}

Although shorter $D M D$ transcripts are more abundant in the brain, full-length gene products are also produced (Table 2). Doorenweerd et al. [81] provide a detailed analysis of the spacial and temporal expression patterns of $D M D$ transcripts in the healthy human brain. Expression from the dystrophin Purkinje promoter in mice produces Dp427p in cerebellar Purkinje cells, but such expression is absent in the human brain throughout development $[81,86]$ suggesting a different role for $\mathrm{Dp} 427 \mathrm{p}$ in mouse than human and questioning the use of mouse models to study the brain in DMD. Interestingly, there is a cerebellar and hippocampal focus to biochemical alterations in DMD brains. Phonological dyslexia and verbal working memory deficits, commonly observed in DMD, are associated with the cerebellum $[32,40,63,93-95]$ and learning and memory are linked to the hippocampus. Cyrulnik in 2008 [21] argued that Duchenne is a cerebellar disorder, and recently in vivo, electrophysiology studies on $m d x$ mice have revealed abnormal cerebellar circuit function [96]. The findings of Doreenweerd et al. in 2017 [81] emphasise the amygdala and hippocampus since it recently transpired that, in contrast to animal studies, $D M D$ expression is highest in the hippocampus and amygdala and lowest in the cerebellum in the human brain.

In contrast to subtle changes in gross anatomy, abnormalities at the microscopic level are robust, with most knowledge arising from studies on the $m d x$ mouse. The absolute number and the packing density of cells in the corticospinal system of $m d x$ mice are $50 \%$ lower than controls and corticospinal neurones were found to have a rounder cell body than pyramidal controls [97]. There is also a significant reduction in hippocampal cell density [98].

Full-length dystrophin co-localises with $\mathrm{GABA}_{\mathrm{A}}$ receptors in the mouse cerebellum, cerebral cortex and hippocampus [99]. $\mathrm{GABA}_{\mathrm{A}}$ clusters are reduced in the $m d x$ amygdala, cerebellum and hippocampus, most notably in cerebellar Purkinje cells, indicating a role for Dp427 in the clustering or stabilisation of $\mathrm{GABA}_{\mathrm{A}}$ receptors in central inhibitory synapses [42, 99]. Similarly, the absence of Dp71 in other models is associated with altered clustering of the water channel aquaporin-4 and the Kir4.1 potassium channel in retinal glial cells as well as altered clustering and maturation of hippocampal neuronal glutamatergic receptors $[58,100]$; these are discussed later in relation to the functional diversity of Dp71. Interestingly, in the $m d x$ mouse brain, Dp71 is found in monomeric form compared with a crosslinker-induced oligomeric state observed in control brains [101].

Positron emission tomography (PET) studies have revealed regional glucose hypometabolism in DMD patients in dystrophin expressing regions. This appears unrelated to motor deficit and is indicative of lowered synaptic activity and is a common characteristic of disorders involving cognitive impairment $[62,102]$. Altered glucose metabolism is also apparent in $m d x$ mice which have significantly decreased free glucose levels and increased glucose use [103]. Like in dystrophic muscle, there are abnormal metabolite ratios in the brains

Table $2 D M D$ gene products expressed in the brain

\begin{tabular}{lll}
\hline$D M D$ product & Expression & Reference(s) \\
\hline Dp427m & Low but detectable throughout brain development & {$[81-83]$} \\
Dp427c & Postsynaptic density of neurones in the cerebral cortex, hippocampus, amygdala and cerebellum & {$[81,82,84,85]$} \\
Dp427p & Purkinje cells & {$[81,86,87]$} \\
Dp260 & Retina & {$[88]$} \\
Dp140 & Cerebral cortex during foetal development with some low expression postnatally in the cerebellum & {$[4,81,88]$} \\
Dp116 & Schwann cells & {$[89]$} \\
Dp71 & Ubiquitous and stable throughout development and adult life & {$[81,90,91]$} \\
Dp40 & Ubiquitous & {$[92]$} \\
\hline
\end{tabular}

$m$ muscle, $c$ cortical, $p$ Purkinje. Splice isoforms are not shown 
of DMD patients and $m d x$ mice such as a higher ratio of inorganic phosphate to ATP $[104,105]$. These altered ratios do not correlate with cognitive profile or genotype and could be related to $\mathrm{CO}_{2}$ retention which is typically associated with neuromuscular disorders $[63,106]$. Conversely, a proton magnetic resonance spectroscopy study by Doorenweerd reported a preserved biochemical composition in human DMD brains when compared with age-matched controls [107].

A chronically sustainable increase in choline-containing compounds has been reported in the frontal cortex and cerebellum of DMD patients and is not thought to be associated with intellectual disability but rather a beneficial compensatory mechanism [61, 103, 108]. In older $m d x$ mice, the increase in choline-containing compounds is confined to the cerebellum and hippocampus [80, 103]. An elevation in cholinecontaining compounds is observed in a number of brain disorders and thought to be indicative of an unsustainable increase in membrane turnover from inflammation or increased cell division $[61,63]$. The fact that in DMD, the increase is sustainable suggests that it is not due to changes in membrane turnover but is rather a permanent change in the level of water-soluble choline-containing compounds [61].

An age-related reduction in the water channel protein aquaporin-4 has been observed in astrocytic end feet surrounding capillaries in the brains of $m d x$ mice. This was accompanied with swelling of the astrocytic perivascular processes which is an early indicator of brain oedema [109]. Altered cellular volumes have been reported in $m d x$ brains [105] but no differences have been found in the response to hypoosmotic shock [103]. A reduction of Dp71 at glial end feet has been shown to alter blood brain barrier (BBB) development which is altered in the $m d x$ mouse $[110,111]$. Dystrophin expression parallels BBB development and perivascular glial arrangement in control mice [110, 112].

In $m d x$ mice, CA1 hippocampal neurones have an increased susceptibility to hypoxia-induced reduction in synaptic transmission, this indicates a role for dystrophin in protecting neurones from hypoxia-induced damage [113]. Biochemical studies on learning and memory appear as conflicting as their behavioural counterparts described above, likely due to the nature of the training procedures used in memory and learning tasks. Sesay et al. [51] report no differences in long-term potentiation (LTP) in CA1 and dentate gyrus areas of the hippocampus in $m d x$ mice compared with controls. Vaillend et al. [50] also reported no change in LTP in either $m d x$ or the $m d x 3 c v$ mouse which has altered expression of all dystrophin gene products. Instead, dystrophin deficiency appears to increase NMDA receptor-mediated short-term potentiation in $m d x$ mice $[50,54,114,115]$, this may be due to the decreased $\mathrm{GABA}_{\mathrm{A}}$ receptor clustering in dystrophindeficient hippocampal neurones [114]. In a later study, using different training paradigms, Vaillend et al. did report enhanced CA1 hippocampal LTP in $m d x$ mice demonstrating that memory defects may be corrected through specific training procedures, such as extended or distributed training [48]. Such altered synaptic plasticity may be responsible for the defects in memory consolidation in learning tasks observed in $m d x$ mice: notably impaired long-term object recognition and impaired long-term spatial memory. An observed reduction in the number of CA1 pyramidal neurones in the anterodorsal hippocampus of $m d x$ mice may also contribute to hippocampal-dependent learning and memory deficits in DMD [98].

In the Dp71-null mouse, the excitation/inhibition balance of the prefrontal cortex is shifted in favour of increased excitation. Whilst inhibitory transmission is unaffected, alterations of AMPA receptor-mediated glutamatergic transmission are apparent along with reduced synaptic plasticity [57]. Helleringer et al. in 2018 also report that Dp71 deficiency increases excitatory transmission [56]. They studied cerebellar physiology and function showing that enhanced transmission at climbing fibres on Purkinje neurones is linked to impairments in synaptic plasticity and the clustering of postsynaptic density protein 95 (PSD-95).

Collectively, both animal and human DMD studies have revealed molecular abnormalities centred around the hippocampus, amygdala and cerebellum. Given the predominance of Dp71 expression in these areas, and indeed the CNS as a whole, to understand the neuropathophysiology of Duchenne, a detailed understanding of this $D M D$ gene product is essential.

\section{Dp71 Gene Expression and Splice Variants}

Dp71 (also known as apo-dystrophin-1) was first described as a $6.5-\mathrm{kb}$ mRNA transcript in 1990 and subsequently confirmed to be encoded by a $4.8-\mathrm{kb}$ mRNA present in all tissues with the exception of skeletal muscle [90, 91, 116-118]. Recently and contradictorily, Dp71 transcript and protein have been detected in skeletal muscle [119]. The promoter is approximately 8 -kb upstream of Dp $427 \mathrm{~m}$ exon 63 , the transcript has a novel first exon encoding a unique seven amino acid Nterminal sequence, MREQLKG [116, 120]. Thereafter, Dp71 shares exons 63-79 with full-length dystrophin which encode for the C-terminal and cysteine-rich domains. Dp71 therefore lacks the whole spectrin-like repeat and N-terminal actinbinding domains of full-length dystrophin, although the novel $\mathrm{N}$-terminus of Dp71 does encode an actin-binding domain sufficient to localise Dp71 to actin filaments [121]. Studies on the promoter reveal it to be a housekeeping-type promoter as expected for ubiquitously expressed genes. It has a high GC content, four potential specificity protein 1 (Sp1)-binding sites and no TATA box [122]. Sp1 is a positive regulator and binds to GC-rich regions in the Dp71 promoter region to help define the transcription start site (Fig. 2). Dp71 is thought to be 
expressed during early myogenesis to aid in cytoskeletal remodelling [121] but its expression is then inactivated in mature muscle to prevent competition with full-length dystrophin for dystrophin-associated protein-binding sites [3, 123]. In contrast, in neurones, Dp71 expression remains strongly induced even in differentiated neurones. Sp1 works with activating protein $2 \alpha$ (AP2 $\alpha$ ) to maintain Dp71 expression, with AP $2 \alpha$ acting as a negative regulator that is released from the AP2 motif during neuronal differentiation (Fig. 2) [124]. Dp71 expression has been shown to be developmentally regulated in several models. Transcript and protein are elevated during cAMP-induced differentiation of rat astrocytes [125] and nerve growth factor (NGF)-induced differentiation of PC12 cells [126, 127]. Sarig et al. [55] studied the differential activity of the Dp71 promoter during mouse development and showed that relatively high Dp71 promoter activity was observed alongside morphogenic events and terminal differentiation in several tissues including the CNS. Of note, the hippocampus showed particularly high activity in line with the latest findings by Doorenweerd [81]. The constitutive expression levels of Dp71 have been shown to be regulated posttranslationally by the ubiquitin proteasome pathway in $\mathrm{PC} 12$ cells with phosphorylation being involved in the proteasomedependent degradation of Dp71 [128].

Unlike muscle, the brain sees the highest regulatory complexity in RNA processing events. It is not surprising that the predominant dystrophin protein variants in the brain are alternatively spliced [129]. Several isoforms of Dp71 have been described as a result of alternative splicing. At the time of writing, we are aware of $14 \mathrm{Dp} 71$ isoforms, although some are yet to be detected at the protein level (Fig. 1 and Table 3). This is in contrast to the recently identified Dp71 in skeletal muscle which is found with all exons intact [119]. Austin et al. [91] in 1995 were the first to characterise four canonical alternatively spliced Dp71 transcripts in cultured human aminocytes. The four isoforms differ according to the presence or absence of exons 71 and 78 (Fig. 1). The absence of exon 78 shifts the reading frame and creates a unique $\mathrm{C}$-terminus by replacing the last 13 amino acids (RNTPGKPMREDTM) with 31 new residues (HNVGSLFHMADDLGRAMESLVSVMTDEEGAE). Dp71 lacking exon 71 was termed Dp71d and Dp71 lacking exon 78 termed the founder sequence, or Dp71f. Subsequently, this terminology was replaced with Dp71a and Dp71b respectively and the isoform missing both exons 71 and 78 termed Dp71ab. A fifth Dp71 isoform, first described in human foetal neural tissue, lacks exons $71-74$ [130, 131]. The additional loss of exons 71-74 (an in-frame deletion of $330 \mathrm{bp}$ ) removes the 110 amino acid syntrophin-binding domain and the isoform is detected as a $58-\mathrm{kDa}$ protein on western blot. The isoform, termed $\mathrm{Dp} 71_{\Delta 110}$, can also be alternatively spliced for exon 78 creating a sixth isoform [131]. To our knowledge, Dp $71_{\Delta 110}$ has only been detected in the CNS where it represents a relatively small proportion of Dp71 isoforms in the brain [131]. In 2012, Saint Martin et al. [132] described a new alternative splicing event in rat PC12 cells that gives rise to the Dp71e isoform. Dp71e retains the last 34 bp of intron 77 that results in a frameshift and premature stop codon preventing the translation of exons 78 and 79. The unique C-terminus of Dp71e is hydrophilic and composed of 10 amino acids, DLSASSSLYY. Subsequently, two Dp71e isoforms with exon 71 or exons $71-74$ removed have been described in rat PC12 cells [133]. Aragon et al. [133] have further extended the repertoire of Dp71 isoforms using mouse brain and retina tissue to identify four new isoforms with varying splicing patterns between exons 71 and 74 (Fig. 1). Finally, the most recently discovered isoform of Dp71 is deleted for exons 68-76 and exon 78 (the smallest yet, predicted to be $25 \mathrm{kDa}$ ) and was described in a glioblastoma cell line and termed $\mathrm{Dp} 71 \mathrm{~b}_{\Delta 68-76}$. Dp71 $b_{\Delta 68-76}$ has a unique C-terminus due to a stop codon in exon 77, the unique amino acids are VRKIFSVLPRTQAQG. These authors also describe an isoform missing exons 71, 73 and 78 termed Dp71ab ${ }_{\triangle 73}$ [134]. Rani report such Dp71'b' type isoforms to be the major type of Dp71 in glioblastoma cell lines. Aragon et al. [135] have demonstrated that the Dp71d group of isoforms is highly expressed in the brain, while the Dp71f group predominates in the retina; Dp71e group is thought to be expressed at very low levels [135].

Dp71 isoforms have a complicated nomenclature. Recently, the multitude of additional splice variants has prompted their grouping according to C-terminal structure. Current, and favoured, nomenclature was described by Aragon et al. in 2018 [135] and is updated here in Fig. 1 and Table 3. In line with this favoured nomenclature and as proposed by Rani et al. [134], the $\mathrm{Dp} 71 \mathrm{~b}_{\Delta 68-76}$ isoform forms a
Fig. 2 The Dp71 promoter region. Dp71 expression during neuronal differentitation is maintained by the combined action of Sp1 and AP2 $\alpha$ as positive and negative regulators respectively. The transcription start site $(+1)$ and Dp71 coding region are indicated

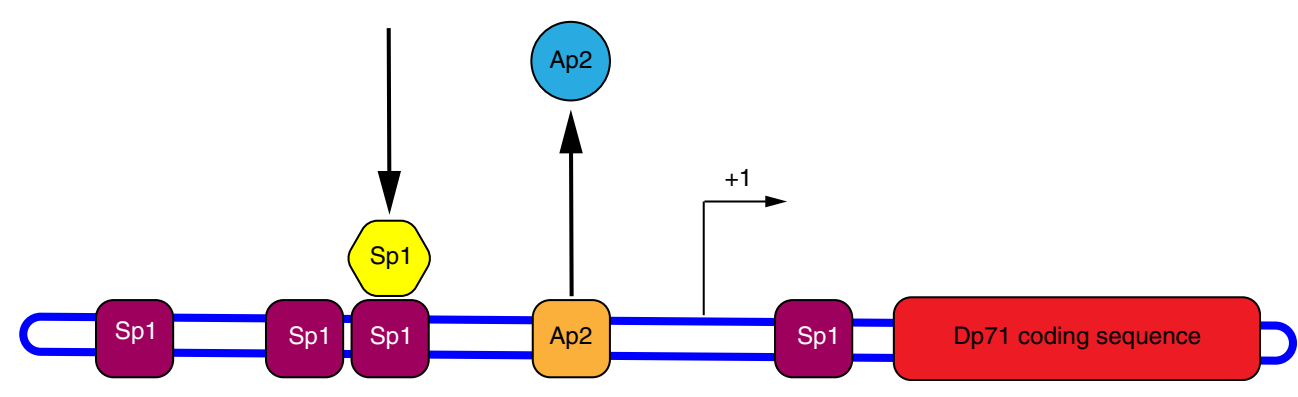


Table 3 Dp71 isoform grouping and nomenclature

\begin{tabular}{|c|c|c|c|c|c|}
\hline Group & Name & Synonym(s) & Reference(s) & Unique C-terminus & $\begin{array}{l}\text { Group specific } \\
\text { antibodies }\end{array}$ \\
\hline \multirow[t]{6}{*}{ d } & Dp71d & Dp71 & [94] & \multirow{6}{*}{$\begin{array}{l}\text { RNTPGKPMREDTM } \\
\begin{array}{|l|l|l|}77 & 78 & 79 \\
\end{array}\end{array}$} & \multirow{6}{*}{$\begin{array}{l}\frac{\text { Dys } 2}{\left.\text { Novacastra }^{\mathrm{TM}}\right)} \\
\text { Reacts with aa } \\
3669-3685 \\
\text { corresponding } \\
\text { to exons } 77-79\end{array}$} \\
\hline & $\operatorname{Dp} 71 d_{\Delta 71}$ & Dp71a & [95] & & \\
\hline & $\operatorname{Dp71d}_{\Delta 74}$ & - & [135] & & \\
\hline & ${\operatorname{Dp} 71 d_{\Delta 71,74}}$ & - & [135] & & \\
\hline & $\operatorname{Dp}_{11 d_{\Delta 71,73-74}}$ & - & {$[135]$} & & \\
\hline & $\operatorname{Dp} 71 \mathrm{~d}_{\Delta 71-74}$ & Dp71c & {$[130,131]$} & & \\
\hline \multirow[t]{5}{*}{ f } & Dp71f & Dp71b & [95] & \multirow{5}{*}{$\begin{array}{l}\text { HNVGSLFHMADDLGRA } \\
\text {-MESLVSVMTDEEGAE } \\
77-79 \mathrm{f}\end{array}$} & \multirow[t]{2}{*}{$\underline{5 \mathrm{~F} 3}[136]$} \\
\hline & $\operatorname{Dp} 71 f_{\Delta 71}$ & Dp71ab & [95] & & \\
\hline & $\operatorname{Dp} 71 f_{\Delta 71,73}$ & $\mathrm{Dp}^{1} \mathrm{ab}_{\Delta 73}$ & [134] & & \multirow{3}{*}{$\begin{array}{l}\text { Reacts with the } \\
31 \text { residue } \\
\text { founder } \\
\text { sequence. }\end{array}$} \\
\hline & $\operatorname{Dp} 71 \mathrm{f}_{\Delta 74}$ & - & [135] & & \\
\hline & Dp71f $f_{\Delta 71-74}$ & $\mathrm{Dp} 71_{\Delta 110}$ & [131] & & \\
\hline \multirow[t]{2}{*}{ e } & $\mathrm{Dp} 71 \mathrm{e}_{\Delta 71}$ & Dp71e & {$[132,133]$} & \multirow{2}{*}{$\begin{array}{l}\text { DLSASSSLYY } \\
\begin{array}{|l|l|}77 \quad i 77 \\
\end{array}\end{array}$} & $\underline{D p 71 e}[132]$ \\
\hline & $\operatorname{Dp}^{2} 1 \mathrm{e}_{\Delta 71-74}$ & Dp71ec & {$[132,133]$} & & $\begin{array}{l}\text { Reacts with the } \\
\text { unique last } 10 \\
\text { residues of } \\
\text { Dp71e. }\end{array}$ \\
\hline g & $\operatorname{Dp} 71 g_{\triangle 68-76}$ & $\begin{array}{l}\text { Dp71g, } \\
\text { Dp71b }_{\triangle 68-76}\end{array}$ & {$[134]$} & $\begin{array}{l}\text { VRKIFSVLPRTQAQG } \\
77\end{array}$ & \\
\hline
\end{tabular}

new group, g, and can be renamed Dp $71 g_{\Delta 68-76}$. The d group of Dp71 isoforms contain exons 78 and 79, the f group lacks exon 78 and has an alternative exon 79 (79f) and the e group contains part of intron 77 (i77) and lacks exons 78 and 79. The $\mathrm{f}$ group isoforms have a more hydrophobic C-terminus than the $\mathrm{d}$ and e groups and can be detected with specific antibodies such as $5 \mathrm{~F} 3[3,136]$. The g group isoform has a stop codon in exon 77.

Although some isoforms have yet to be detected at the protein level, it is clear that RNA processing is responsible for the ubiquity and functional diversity of Dp71 in the brain.

\section{Functional Diversity of Dp71}

The multitude of Dp71 isoforms described above makes functional studies difficult. Many studies and reviews concerning the DMD neuropsychiatric syndrome have considered Dp71 a single protein and many use a pan Dp71 antibody unable to discriminate between splice isoforms. It is important that the repertoire of isoforms in a chosen model be established alongside any functional studies. This has been done for example in a glioblastoma cell line [134] and PC12 cells [133], the latter being the most common cellular model to asses Dp71 function. PC12 cells are derived from a pheochromocytoma of the rat adrenal medulla. The tissue has an embryonic origin from the neural crest with populations of neuroblastic cells. It must be noted that this model system has some limitations for the study of the human nervous system. In this review, the term Dp71 should be taken to encompass the whole family of isoforms unless otherwise stated; where specific splice isoform data is available, we use current nomenclature described above.

A canonical function of Dp71 in the brain relates to the clustering of the water channel aquaporin-4 (AQP4) and the inwardly rectifying potassium channel Kir4.1 in retinal Müller glial cells $[137,138]$. It is well documented that DMD patients with mutations towards the centre and 3 ' end of the DMD gene have an abnormal electroretinogram. Retinal Müller glial cells are responsible for maintaining retinal homeostasis; Dp71 is the only dystrophin gene product expressed in these cells and it anchors AQP4 and Kir4.1 channels at the glial perivascular end-feet which are essential for osmoregulation and potassium buffering respectively (Fig. 3) [139, 140]. Retinal Müller glial cells are a common cell model used to study Dp71 [3] and a clear role for Dp71 in retinal osmoregulation and vascular permeability of the retina is established. A role for Dp71 in the clustering of ion channels and receptors is not limited to glial cells with Dp71 reported to play a role in the clustering and maturation of glutamatergic receptors in hippocampal neurones (Fig. 4) [58]. Dp71-null mice have increased excitatory transmission, aberrant synapse density, organisation and maturation as well as reduced synaptic plasticity in the CA1 hippocampus $[58,100]$. Beyond these roles in glia, synapse 
Fig. 3 The canonical nonneuronal role of Dp71. In the retina, Dp71 anchors aquaporin 4 (AQP4) and the inwardly rectifying potassium channel (Kir4.1) at the glial perivascular end-feet of Müller glial cells. $\alpha$-syn, alphasyntrophin

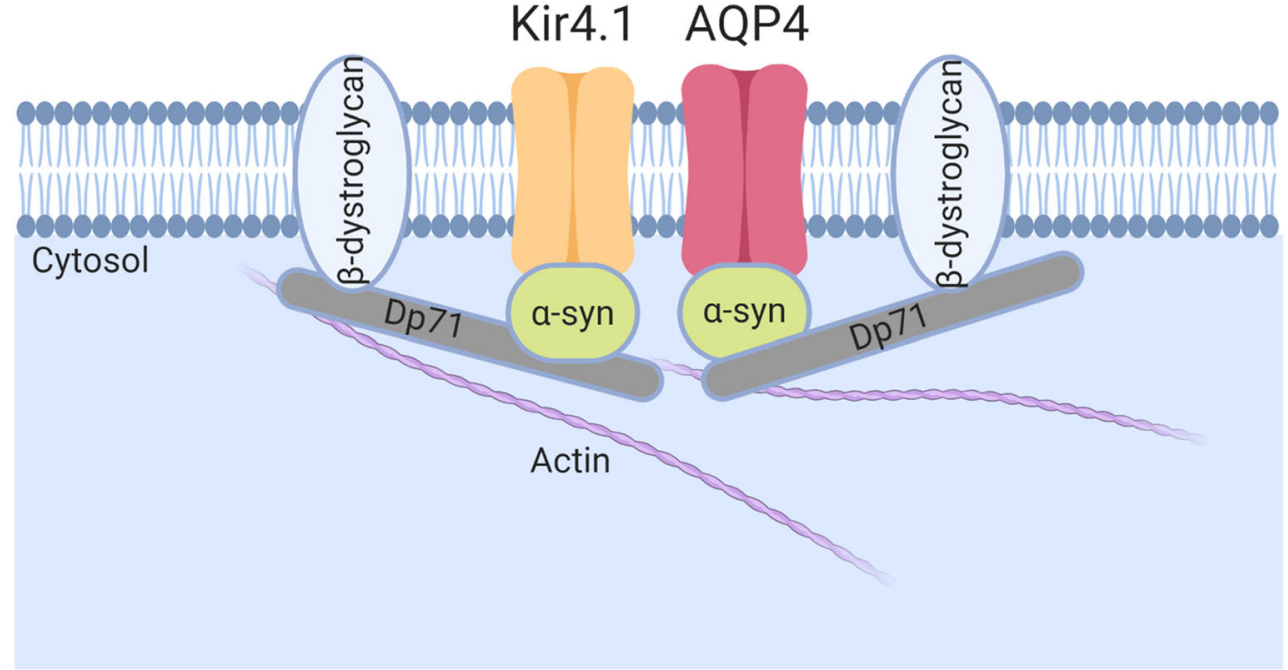

functions and neuronal excitability, the emerging complexity of Dp71 splice isoforms and their differential subcellular localisations has led to an expanding repertoire of functions which we discuss below.

Dp71 has long been confirmed a cytoskeletal plasma membrane-associated protein in various tissues and cells including cultured rat brain astrocytes [3]. Like full-length dystrophin in muscle, Dp71 forms a dystrophin-associated protein complex (DAPC) in the brain [3]. Dp71 therefore retains some recognisable functionality of full-length dystrophin through binding with dystroglycans, dystrobrevins and syntrophins since their binding domains are located near the C-terminus. The dystroglycan-binding site on dystrophin has been delineated to amino acids 3054-3271 (spanning exons 61-68, [141]) whilst syntrophin-binding sites are coded by exons 73-74 [142]. Although Dp71 is able to restore the DAPC in skeletal muscle, it does not compensate for the lost function of Dp427; thus, even though Dp71 interacts with some of the same proteins, it likely has different functions than full-length dystrophin [91]. The existence of Dp71 splice isoforms without the capacity to bind such dystrophin-associated proteins demonstrates a complex functional diversity regulated via RNA processing. Blake et al. [143] indicate differences in DAPC composition between neurones and glia and show Dp71 to be associated with $\alpha$-dystrobrevin-1 and syntrophin in glia; interestingly, such complexes are still formed in $m d x 3 c v$ mice which lack C-terminal dystrophins, although later studies have shown disruption of such complexes in these mice [144]. Dp71-DAPCs in several tissues have since been characterised and revealed to differ according to cell type and microenvironment (reviewed by [3]). Dp71-DAPCs in the CNS contain the following: $\beta$-dystroglycan, $\delta$-sarcoglycan, $\alpha 1$-syntrophin in rat retinal Müller glial cells [145] and $\alpha$ dystrobrevin-1, $\alpha 1$ - and $\beta 2$-syntrophin, and $\alpha$ - and $\beta$ dystroglycan in glial end-feet and vascular endothelial cells [144]. In undifferentiated PC12 cells, Dp71f $\mathrm{f}_{\Delta 71}$ is associated with $\beta$-dystroglycan, $\beta 1$-syntrophin, $\beta$-dystrobrevin and $\alpha$-, $\beta$-, and $\gamma$-sarcoglycan [146]. During NGF-induced differentiation, the complex is altered to contain $\beta$-dystroglycan, $\alpha 1$ syntrophin, $\beta$-dystrobrevin, $\gamma$-sarcoglycan and neuronal nitric oxide synthase (nNOS). The latter hints at an involvement for Dp71f $f_{\Delta 71}$ in signal transduction during neuronal differentiation [146].

A role for Dp71 in neuronal differentiation is supported by the fact that Dp71d and $\mathrm{f}$ are upregulated during PC12 cell differentiation. Reduced Dp71 expression inhibits NGF-
Fig. 4 A proposed synaptic function for Dp71. Dp71 organises glutamate receptor distribution at the postsynaptic density. The exact position and binding of Dp71 in relation to PSD-95 and particular receptors is unclear

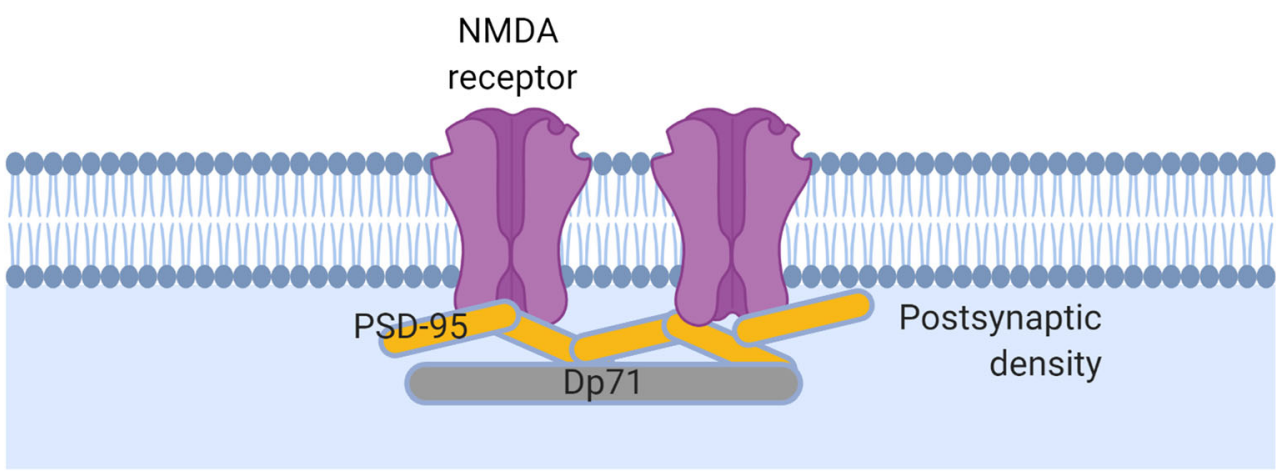


induced neurite outgrowth and neuronal differentiation in PC12 cells [147]. Acosta et al. show that the late differentiation marker, microtubule-associated protein 2 (MAP2) is inhibited along with Dp71 and that the loss of Dp71 also correlates with altered dystrophin-associated protein expression. Furthermore, Aragon et al. 2016 [133] identified Dp71 isoforms in PC12 cells localised to neurite extensions and growth cones suggesting a role in differentiation and neurite growth, also supported by [58] who show Dp71f expression in the growth cones of cultured neurones from Dp71-null mice, more so in excitatory synapses. The splice isoform Dp71 $\mathrm{e}_{\Delta 71}$ has also recently been shown to have a role in neurite outgrowth in PC12 cells through regulating the expression of the cytoskeletal proteins HspB1, S110A6 and K8 as well as the HCNP protein involved in neurotransmitter synthesis [148]. These authors overexpressed Dp71 $\mathrm{e}_{\Delta 71}$ during neuronal differentiation and found overexpression to increase neuronal differentiation and alter the expression profile. Cytoskeletal reorganisation and neurotransmitter synthesis are both required for differentiation which appears a key role for Dp71 in neurones. In support of these findings, the same group generated a Dp71 mutant lacking exons 78 and 79 , Dp7 $1_{\triangle 78-79}$ which they show to stimulate PC12 proliferation [149], cell differentiation [150] and neurite outgrowth through the phosphorylation of HspB1 [151].

Dp71 expression is not confined to the plasma membrane indicating it has different functions within the same cell (Fig. 5). Both Dp71d and Dp71f have been found in cultured neuronal nuclei [152]. Using Dp71 group-specific antibodies, Dp71d was found within nuclear granules in both neurones and astrocytes whilst Dp71f nuclear staining was only observed in neurones [152]. Dp71f and Dp71f $f_{\Delta 71}$ are also localised to the nucleus of HEK293 cells with Dp71f appearing more dominant and Dp71f $f_{\Delta 71}$ specific to only the nucleus [153]. Alternative splicing determines the subcellular localisation of Dp71. Using GFPtagged constructs with or without exons 71 and 78, Gonzalez et al. [154] determined that the construct lacking both exons 71 and $78\left(\mathrm{Dp}_{\left.11 \mathrm{f}_{\Delta 71}\right)}\right)$ is found exclusively in the cytoplasm of HeLa, C2C12 and N1E-115 cells whilst Dp71d $\mathrm{d}_{\Delta 71}$ was found exclusively in the nucleus. Dp71d and Dp71f, containing exon 71 , had both nuclear and cytoplasmic localisations. Marquez in 2003 [127] later confirmed the exclusive localisation of Dp71d $_{\Delta 71}$ and Dp71f ${ }_{\Delta 71}$ to the nucleus and cytoplasm of PC12 cells respectively. The presence of either exon 71 or exon 78 therefore appears to determine the subcellular localisation of Dp71. Furthermore, during NGF-induced PC12 cell differentiation, Dp71f ${ }_{\Delta 71}$ relocates from the cytoplasm to neuritic processes such as the growth cone and Dp71d $\mathrm{d}_{\Delta 71}$ appears to relocate almost entirely to the nucleus where it binds the nuclear matrix during the late stages of neuronal differentiation in $\mathrm{PC} 12$ cells (Fig. 5) [127, 155], thus not only are Dp71 levels upregulated but there is a differential subcellular localisation of Dp71 isoforms during neuronal differentiation. Garcia Cruz et al. [148] also document an increase in nuclear expression of Dp $71 \mathrm{e}_{\Delta 71}$ during neuronal differentiation. Interestingly, throughout the process of differentiation, Dp71 maintains a co-localisation with $\beta$-dystroglycan, including during the relocation of $D p 71 d_{\Delta 71}$ to the nucleus where levels of $\beta$-dystroglycan are also increased [127]. Dp71 is known to interact directly with $\beta$-dystroglycan, the most abundant dystrophin-associated protein that binds intracellularly to dystrophin and extracellularly to $\alpha$-dystroglycan forming a strengthening link between the extra cellular matrix and the cytoplasm [156]. Thus, it is suggested that a Dp71-containing DAPC exists in the nucleus of neuronal cells. Indeed, Dp71 co-immunoprecipitates with sarcoglycans, $\beta$-dystroglycan, syntrophins and dystrobrevins in HeLa, C2C12 and PC12 nuclear fractions where a nuclear DAPC is formed [3, 157-159].

Dp71 does not contain a nuclear localisation signal (NLS) but, like other nuclear proteins, phosphorylation appears to regulate its nuclear transport. $D p 71 d_{\Delta 71}$ is phosphorylated at serine and threonine residues in PC12 cells by protein kinase $\mathrm{C}$ (PKC) and the $\mathrm{Ca} 2+/$ calmodulin-dependent protein kinase II (CaMKII) with NGF treatment stimulating phosphorylation and CaMKII-phosphorylated Dp71d favouring a nuclear localisation (Fig. 5) [155]. It is suggested that a CaMKII phosphorylation site located in exon 79 modulates the nuclear localisation of $D p 71 d_{\Delta 71}$ since this site is not present in the unique C-terminus of Dp71f group isoforms. Phosphorylation of dystrophin is known to mediate its interactions with members of the DAPC and actin [155] and $\beta$-dystroglycan contains a NLS [160]; therefore, Dp71 may access the nucleus through its interaction with $\beta$-dystroglycan [3]. More recently, it was determined using truncation mutants in $\mathrm{C} 2 \mathrm{C} 12$ cells that Dp71d shuttles between the nucleus and cytoplasm through association with importin (IMP) $\alpha / \beta$ and the exportin CRM1 [161]. These authors found the cysteine-rich zincfinger ZZ domain is required for import and that Dp71 likely utilises microtubules and the motor protein dynein for retrograde transport to the nucleus from the plasma membrane [161]. The alternative splicing of Dp71 may control phosphorylation events (and ultimately function) since phosphorylation of Dp71 by cyclin-dependent kinase 1 (CDK1) occurs at a site in exon 78; such a site is not present in utrophin, a protein with high homology to dystrophin [91]. Thus, Dp71 is precisely and differentially regulated during PC12 cell differentiation.

Besides the plasma membrane and nucleus, Dp71d and Dp71f group isoforms have been observed in the Golgi apparatus and Dp71d in the neurofilament cytoskeleton [152]. Dp71d group isoforms are also reported to be localised in microsomes and a Dp71f-like protein is expressed in mitochondria of $m d x 3 c v$ mice [162].

Taken together, RNA processing is important for the correct localisation and function of dystrophin in the brain with the $\mathrm{C}$-terminal end in particular determining the location and thus function of each isoform. 


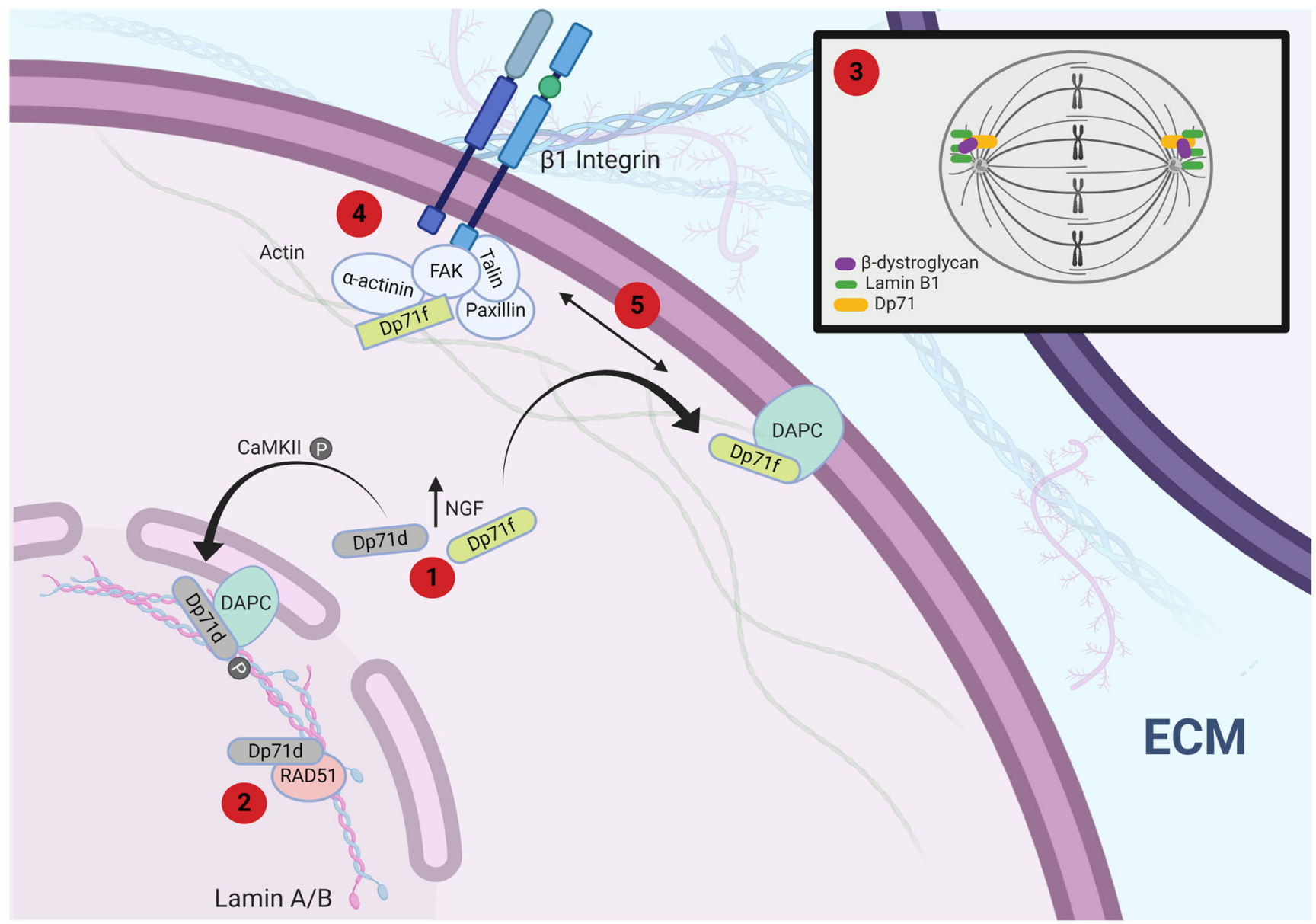

Fig. 5 Multiple non-synaptic roles of Dp71. (1) Upon NGF-induced differentiation, Dp71d is phosphorylated by CaMKII and relocates to the nucleus where it forms a nuclear DAPC and may mediate nuclear responses during NGF signalling. In contrast, Dp71f moves to the cell surface and localises with the DAPC in areas such as the growth cone to play a role in neurite outgrowth. (2) Nuclear Dp71d binds to the DNA

\section{Adhesion}

Given Dp71 isoforms are differentially expressed and localised during neuronal differentiation and the apparent role of Dp71 in signalling during neuronal differentiation, it is unsurprising a role for $\mathrm{Dp} 71$ in adhesion has been described given that adhesion and differentiation are closely linked.

The DAPC is known to interact with the integrin adhesion system including proteins such as the integrins, viniculin, talin, paxillin and focal adhesion kinase (FAK); evidence now links Dp71 with cell adhesion in the brain [3]. In the glioblastoma cell line, U-373 MG Garcia-Tovar et al. showed a Dp71f group isoform localised to the focal complex and leading borders of lamellipodia where it co-localises with vinculin, $\beta 1$-integrin and $\alpha$-actinin [163]. Dp71 $\mathrm{f}_{\Delta 71-74}$ and Dp71d $\mathrm{d}_{\Delta 71-74}$ also appear to be involved in the remodelling of the platelet cytoskeleton where in $m d x 3 c v$ mice thrombinmediated platelet adhesion is impaired [3, 164]. Dp $71 \mathrm{f}_{\Delta 71}$ binds to the adhesion complex in PC12 cells, associating with repair protein, RAD51. It also plays a role during cell division (3). (4) $\mathrm{Dp} 71 \mathrm{f}$ is a facilitator of cell adhesion and binds to the $\beta 1$-integrin adhesion complex. (5) Dp71 aids in cross-communication between the DAPC and the $\beta 1$-integrin adhesion complex. Figure created with Biorender. com

FAK, $\beta 1$-integrin, actin, talin and $\alpha$-actinin (Fig. 5) [165, 166]. The depletion of $\mathrm{Dp} 71$ results in a reduction of $\beta 1$ integrin adhesion complex components and deficient adhesion to laminin [166]. Cerna et al. further demonstrate that Dp71 $f_{\Delta 71}$ binds directly to FAK and $\beta 1$-integrin, thus Dp71 is a structural component of the $\beta 1$-integrin adhesion complex in PC12 cells required for correct function and/or assembly and stability [166]. Interestingly, in the study by Cerna, $\beta$ dystroglycan was not detected in immunoprecipitates of $\beta 1$ integrin and FAK suggesting the binding of $\beta$-dystroglycan to Dp71 is out of the context of the adhesion complex.

Adhesion, neurite outgrowth and differentiation are closely linked, it is proposed that the deficient adhesion activity of Dp71f $\mathrm{f}_{\Delta 71}$-depleted PC12 cells is responsible for their lack of NGF-induced neurite outgrowth [3, 147]. Cerna et al. proposed a model which we update in Fig. 5 of how Dp71f $f_{\Delta 71}$ associates with the $\beta 1$-integrin adhesion complex. Its association with $\alpha$-actinin suggests crosstalk between the Dp71containing DAPC and the adhesion complex with Dp71 
conferring stability [166]. Such intricate functions require investigation in DMD and human-derived model systems.

\section{Cell Division}

Dp71 depletion studies in PC12 cells have revealed a role in cell division. Dp71-depleted cells have reduced growth with a delay in $\mathrm{G0} / \mathrm{G} 1$ transition and an increase in apoptosis during nocodazole-induced mitotic arrest [167]. Dp71 localises with lamin B1 and $\beta$-dystroglycan (which are involved in cell division, $[168,169])$ at the mitotic spindle poles, cleavage furrow and midbody, these proteins are reduced at these sites upon Dp71 depletion in PC12 cells [167]. Dp71 is therefore considered a component of the mitotic spindle and cytokinesis protein complexes and could modulate the cell division cycle through interactions with lamin B1 and $\beta$-dystroglycan (Fig. 5). Based on the antibodies used and knowledge of Dp71 isoform expression in $\mathrm{PC} 12$ cells, the $\mathrm{Dp} 71 \mathrm{~d}_{\Delta 71}$ splice variant with predominant nuclear localisation and an intact exon 78 is implicated here.

Of relevance to a role in cell division, it is interesting to note the poorly defined, but intriguing, role of dystrophin, and Dp71 in particular, in tumourigenesis where its association with proteins such as FAK implicate Dp71 in cell migration and invasion [170, 171]. This has been reviewed by [172] and is outside the scope of this review.

\section{Nuclear Function(s)}

The proposed role of Dp71 in the nucleus is primarily as a scaffolding protein at the nuclear envelope [3]. This is supported by the presence of nuclear Dp71d group containing DAPC complexes and the presence of Dp71d in the nuclear matrix and/or envelope in various cell lines as discussed above (Fig. 5). Dp71 also directly interacts with the nuclear envelope protein lamin B1 $[157,158]$. Such a nuclear scaffolding role implicates Dp71, indirectly, in nuclei morphology, gene expression and DNA repair since these functions, and others, utilise the support of the nuclear matrix and/or envelope. The nuclear envelope consists of two lipid bilayer membranes and nuclear pore complexes. Lamins are intermediate filaments associated with the inner nuclear membrane and are the principle component of the nuclear matrix. Nuclear matrix-associated Dp71d $\mathrm{d}_{\Delta 71}$ increases during neuronal NGF-induced differentiation and relocates from the periphery of the nuclear matrix to the centre of the nucleoskeletal structure [173]. The depletion of Dp71 results in reduced levels of lamin B1 and the mislocalisation of emerin, an integral protein of the inner nuclear membrane $[167,173]$. Such changes to $D p 71 d_{\Delta 71}$ localisation and expression demonstrate the dynamic nature of Dp71d $\mathrm{d}_{\Delta 71}$ in the nucleus and further evidences the role of Dp71 during neuronal differentiation. To further support an extended role for Dp71 in nuclear functions, Dp71 has been shown through immunoprecipitation and immunocytochemistry to bind to RAD51 in human bronchial epithelial cells [174]. These authors do not determine the specific isoform(s) of Dp71 in their study but depletion of Dp71 increases DNA damage and $\mathrm{H}_{2} \mathrm{O}_{2}$-induced apoptosis. $\mathrm{RAD} 51$ is a protein involved in homologous recombination repair upon DNA damage; it additionally binds to lamin B1 (Fig. 5) and its binding to Dp71 in epithelial cells warrants further investigation in neuronal cell models as does the overall nuclear function of Dp71 in DMD and human-derived model systems.

Dp71 functions are diverse but they include closely related processes such as differentiation, neurite outgrowth and cell adhesion. It would be interesting for future studies to delineate the Dp71-binding sites and isoform specificity of proteinprotein interactions in relation to the functions described above. Utrophin is a foetal homologue of dystrophin and is regarded as a potential replacement for dystrophin loss in DMD. Interestingly, utrophin upregulation in the brain does not ameliorate the behavioural deficits in $m d x$ mice [175] highlighting the functional importance of specific $D M D$ gene products such as Dp71 in the brain and their association to the neuropathophysiology of the disease.

\section{Role of Dp71 in the Neuropathophysiology of DMD}

\section{Genotype-Phenotype Correlations}

The existence of 'hot-spots' for $D M D$ gene mutations, and exceptions to the reading frame hypothesis [2], has instigated many DMD and Becker muscular dystrophy (BMD) genotype-phenotype relationship studies. BMD is a milder condition caused by in-frame mutations in the $D M D$ gene, BMD patients express varying levels of dystrophin protein. Enhanced genetic testing and genotype definition in the dystrophinopathies has led to a growing understanding of the genotype-phenotype relationship that is proving beneficial for diagnostic and treatment purposes [2, 176, 177].

Original studies in the 1990s showed no genotype-phenotype correlation in relation to the DMD neuropsychiatric syndrome, but these were conducted with limited understanding of Cterminal dystrophin gene products and the complexity of the $D M D$ gene $[2,178,179]$. It is now clear that the frequency and severity of CNS involvement increase with the accumulated loss of distal dystrophin gene products, with $D M D$ mutations after exon 63 (and therefore Dp71 loss) associated with the most severe intellectual impairment [2, 7-9, 11, 180-182]. Mutations located after exon 63 are rare and affect the expression of Dp71, as well as all other brain $D M D$ gene products. All individuals with mutations disrupting Dp71 expression reported to date have severe intellectual impairment, it has even been known for brain comorbidities such as autism to precede a diagnosis of Duchenne 
[2]. Desguerre et al. in 2009 identified four sub-populations of DMD based on the severity of muscle and brain dysfunction; they show that mutations upstream of exon 30 correlated well with spared cognition but not motor function [183]. Most recently, it is reported that, in steroid-naïve boys with dystrophinopathy, speech delay and learning difficulties are more common in boys with mutations downstream of DMD exon 45 [39]. In 1998, Moizard et al. reported two patients with severe intellectual disability with $D M D$ mutations altering Dp71 transcripts [7]. The same group later demonstrated amongst a larger cohort without $D M D$ deletions or duplications who have severe intellectual impairment that all patients with point mutations resulting in the termination of Dp71 expression were the most severely affected [8]. A large study on $81 \mathrm{DMD}$ and BMD patients with mutations either affecting all dystrophin gene products (54 patients) or all products except Dp71 (27 patients) found that the BMD patients with intellectual disability had mutations affecting Dp71 expression and that mutations upstream of exon 62 in DMD patients are associated with normal to borderline cognitive performance [6]. Ricotti et al. add further support in an even larger multicentre study of 130 DMD patients reporting a higher incidence of intellectual disability in 14 patients with distal $D M D$ mutations affecting all gene products [13]. They report $64 \%$ of individuals with mutations affecting Dp71 had intellectual disability compared with $25 \%$ of those with mutations affecting Dp260, Dp140 and Dp116, whilst only $15 \%$ of patients presented with intellectual disability when the mutations only affected full-length dystrophin [13]. The group with Dp71 disrupting mutations also had the most severely affected working memory and highest Social Communication Disorder Checklist (SCDC) score.

\section{Tissue and Cellular Evidence}

The localisation and function of Dp71 variants in the brain combined with the genotype-phenotype observations described above provide strong support for the involvement of Dp71 in cognitive impairment and the DMD neuropsychiatric syndrome. There are conflicting reports concerning the level to which Dp71 expression is affected in $m d x$ mice. Nico et al. show reduced levels of Dp71 in the brains of $m d x$ mice compared with controls indicating that $m d x$ mice may be a model of Dp71 deficiency [184]. However, this is contradicted in other studies including in our own unpublished data. An important model for understanding how Dp71 loss can contribute to cognitive impairment is the Dp71-null mouse. Daoud et al. in 2009 carried out the first detailed functional and behavioural characterisation of the brain in these mice [58]. Cultured primary neurones had abnormal glutamatergic synapse maturation and organisation and altered synapse density [58]. Glutamatergic transmission was enhanced and synaptic plasticity reduced in the CA1 hippocampus. These mice have a reduced exploratory and novelty-seeking behaviour as well as deficits in spatial learning and memory [58]. Dp71-null mice display altered expression of some, but not all, DAPC proteins, for example $\beta$-dystroglycan and $\alpha$-syntrophin expressions are reduced whilst $\gamma 1$-syntrophin is overexpressed by more than $200 \%, \alpha$-dystrobrevins were unchanged indicating a requirement of $\mathrm{Dp} 71$ for the anchoring of some but not all DAPC proteins [58]. Dp71 loss in cultured neurones from these mice affected the clustering and distribution of the synaptic proteins type-1 vesicular glutamate transporter (VGLUT1) and PSD-95; Dp71 loss is believed to increase the stabilisation and/or local translation of PSD-95 [56, 58]. The mice have abnormally large clusters of PSD-95 and a reduced number of excitatory synapses. Dp71 therefore may organise glutamate receptor distribution (Fig. 4). Dp71-null mice have reduced synapse density and the morphology of the postsynaptic active zone is disrupted. Daoud et al. suggest that a postsynaptic mechanism contributes to the enhanced synaptic transmission in Dp71-null mice [58]. The unusual accumulation of PSD-95 in Dp71-null synapses could increase NMDAr gating and delivery to the synapse thus increasing AMPAr currents. Thus the role of Dp71 is not directly in synaptic plasticity but rather organisation and maturation of the synapse.

The morphogenesis and plasticity of the synapse are known to play a role in intellectual disability [185] and thus it can be speculated that the lower IQ levels observed in DMD patients may be explained by altered synapse organisation and maturation. The behavioural characteristics of the Dp71-null mouse are also in agreement. These mice display reduced exploratory behaviour, slight retention deficits in inhibitory avoidance and impaired spatial learning and memory [58]. Deficits in exploratory behaviour have been linked to enhanced glutamatergic transmission [186], although this behaviour to our knowledge has not been specifically assessed in DMD patients although could be postulated from the clinical observations discussed earlier. Dp71-null mice have more severe learning impairments than $m d x$ mice supporting the view that Dp71 plays a role in the neuropathophysiology of DMD. The respective and combined involvement of both GABAergic and glutamatergic functions in the basis of intellectual disability in DMD remains to be elucidated; since unlike Dp71-null mice, in DMD patients, a cumulative loss of Dp427, Dp140 and Dp71 is likely a key contributor to the severity of brain involvement in DMD. Further studies on the $m d x 3 c v$ mouse model may shed light here, although compensatory mechanisms such as from the small level of Dp427 present add a complication.

Induced pluripotent stem cells (iPSCs) prepared from patient-derived blood or fibroblasts are fast becoming an important tool for studying the disease pathogenesis and represent a human model to study the neuropathogenesis of DMD. The latest technology has seen the differentitation of skeletal muscle cells that recapitulate key DMD disease features [187]. In 2019, two papers described alterations in iPSC-derived 
neurones and astrocytes from DMD patients with variable deletions. Patel et al. characterised five DMD astrocytic lines from patients with deletions affecting the expression of either Dp427, Dp427 and Dp260 or Dp427, Dp260 and Dp140 [188]. Behavioural problems or autism is described in three patients, all of which have mutations affecting all three $D M D$ gene products. Interestingly, cortical neuronal progeny from these patients did not show any obvious abnormalities consistent with the fact that neurones do not express Dp427 in sufficient amounts and Dp71 remains unaffected in these lines. Cytoskeletal abnormalities (increased cell area, volume and branching), alterations in $\mathrm{Ca}^{2+}$ handling and nitric oxide signalling were observed in iPSC-derived astrocytes from DMD patients when compared with controls. Patel demonstrate that iPSC-derived astrocytes from DMD patients have significant defects in glutamate handling with decreased glutamate uptake/consumption, they find that increased new production of glutamate by these astrocytes in turn causes neuronal defects such as decreased neurite outgrowth and hyperexcitability and reactive astrogliosis. It is interesting that $\mathrm{Dp} 71$ is preserved in these astrocytes and studies using iPSC-derived from DMD patients with mutations affecting Dp71 are warranted. Ruggieri et al. in 2019 report on iPSC-derived neurones (glutamatergic sensory lineages) from a DMD patient with a mutation in intron 70 and reduced Dp71 expression in the derived cells [189]. The patient has mid-level intellectual disability. iPSC-derived neurones from this patient were smaller in both perimeter and surface area and have irregular nuclei compared with control; adult neural stem cells from $m d x$ mice are also reduced in size [111]. Using the pan-Dp71 antibody MANDRA1, Dp71 was not strongly associated with the membrane and scattered in the cytoplasm in contrast to the control. DMD-differentiated neurones were able to produce an action potential but were more typically unipolar or bipolar compared with the multipolar controls, DMD neurones presented with more strongly spread out processes than controls. Ultrastructurally, the patient neurones had dilated processes containing autophagic vacuoles. Ruggieri et al. report an increase in the expression of the sarco/endoplasmic reticulum $\mathrm{Ca}^{2+}$ ATPase (SERCA2) pump in iPSC-derived neurones from the DMD patient as well as cytosolic $\mathrm{Ca}^{2+}$ overload. SERCA2 is located on the endoplasmic reticulum (ER) membrane and is a key protein responsible for clearing intracellular $\mathrm{Ca}^{2+}$. SERCA2 dysregulation is implicated in disorders affecting cognitive ability [190]. Thus, $\mathrm{Ca}^{2+}$ dyshomeostasis occurs in Dp71-reduced sensory neurones as well as in skeletal muscle. An increase in the release of $\mathrm{Ca}^{2+}$ from intracellular stores (SR/ER) is associated with spatial learning deficit in $m d x$ mice since a reduction of $\left[\mathrm{Ca}^{2+}\right] \mathrm{i}$ improves cognitive function in $m d x$ mice [191]. This is the first study from a human model demonstrating abnormalities in Dp71-deficient neurones that are associated with cognitive impairment. Further studies on iPSC-derived neuronal and glial cells from Dp-71-deficient
DMD patients are required to elucidate the precise cellular processes and mechanisms that may contribute to the neuropathogenesis of DMD.

Using transcriptomic data from Allen Human Brain and BrainSpan atlases, co-expression analysis of Dp427, Dp170 and Dp71 + Dp40 has revealed an association with genes involved in neurodevelopmental disorders [81]. Genes coexpressed with Dp71 + Dp40 (undifferentiated in this study) were enriched in gene ontology terms related to wound healing, cell motility, actin cytoskeleton and receptor binding. The top phenotype identified was abnormal cerebral vasculature. This Doorenweerd et al. study implies that the structural abnormalities identified in the brains of patients lacking Dp427 and Dp140 are aggravated further in patients also missing Dp71 and Dp40. Several X-linked developmental disorders linked to intellectual impairment are associated with proteins involved in regulating cytoskeletal organisation at excitatory synapses [185]. Further, abnormal neuronal migration during development is associated with autism spectrum disorders [192]. Given Dp71 binds to key regulators of this process such as FAK and $\beta 1$-integrin, we investigated a role for Dp71 in cell migration finding that DMD patient-derived fibroblast cell lines lacking Dp71 migrate at a faster rate than control [170]. $\beta 1$-integrin-meditated cell adhesion modulates neuronal migration and synaptogenesis during central nervous system development [193]. It is reasonable to suggest that neuronal migration be disturbed in DMD patients lacking Dp71. In support of this, work by Niks et al. [194] suggests that the changes in the DMD brain are structural and indicate perturbed brain development as opposed to progressive cerebral damage. Indeed, cerebral heterotopia, where neurones do not migrate properly, has been recorded upon autopsy in 1988 where it was also suggested abnormal dendritic development and branching may underlie intellectual impairment [66]. The increased excitation in prefrontal networks identified in the Dp71-null mouse affects executive functions critical for intellectual function in humans [57]. In line with alterations in neurodevelopment, excitation/inhibition imbalance along with executive dysfunctions is associated with the pathogenesis of neurodevelopmental disorders comorbid for intellectual disability and neuropsychiatric disorders [57].

Glial cells have an important physiological role in regulating neuronal excitability through the buffering of potassium; abnormal potassium clearance is linked to epilepsy [195]. The incidence of epilepsy in DMD patients can convincingly be tied to dystrophin expression and the absence of Dp71 in particular. This has been reviewed in [196]. For example, Dp71 is preferentially expressed in the amygdala and hippocampus, two areas associated with epileptogenesis and the functions of Dp71 in the clustering of potassium channels and maintaining BBB integrity are also strongly linked to epilepsy. 
An altered prevalence of AQP4 and Dp71 is observed in the neurodegenerative disease idiopathic normal pressure hydrocephalus (iNPH) and their dysfunction is associated with slowly evolving neurodegeneration in this condition [197]. Neurodegeneration as a concept has not been explored in Duchenne since there is a presumption that the neuropsychiatric phenotype as a whole is not progressive. Pairing recent insights into the function and involvement of Dp71 in the neuropathophysiology of DMD with original autopsy findings of cerebral heterotopia, neuronal loss, gliosis and Purkinje cell loss [66] is worth exploring.

\section{Conclusion}

The high risk of neuropsychiatric syndromes in DMD patients warrants early intervention to achieve the best possible quality of life. We have entered an unprecedented era in DMD research with new drugs entering the market that can restore dystrophin expression in the muscle. These include antisense oligonucleotide-based therapies targeting hotspot $D M D$ mutations between exons 45 and 53 (e.g. Exondys51, eteplirsen) and Translarna (Ataluren) which targets nonsense mutations $[198,199]$. Unravelling the function and pathophysiological significance of dystrophin in the brain has become a high research priority in order to treat every element of Duchenne. A clear role for Dp71 in the neuropathogenesis of DMD is described. Further studies are required to elucidate exact mechanisms in humans, particularly regarding neurodevelopmental defects. To this end, the emergence of iPSC and organoid models will be important as well as the availability of donated human Duchenne brain tissue. Future research should also explore the interplay between Dp140 and Dp71 given the apparent neurodevelopmental origin of some DMD brain comorbidities.

RNA processing critically regulates the localisation and function(s) of Dp71 in the brain, yet we understand very little about how the $D M D$ gene is regulated in this way and whether there are disruptions in Duchenne. Indeed, aberrant RNA processing is a common mechanism of disease for neurological disorders [200] and studies on the neuronal RNA processing of $D M D$ may help inform ongoing drug development. Evidence shows current DMD gene therapy approaches can be used to treat the DMD brain with most studies using exon skipping to restore the reading frame and production of an internally truncated dystrophin protein [201]. For example, an AAV exon skipping vector has been delivered to the $m d x$ brain resulting in improvements in hippocampal function [202]. In another study, the abnormal freezing response of $m d x$ mice was rescued by intracerebroventricular delivery of an antisense oligonucleotide designed for $D M D$ exon skipping [42]. Continuing improvements in the chemistry of oligonucleotides are resulting in better brain targeting, for example
tricyclo-DNA antisense oligonucleotides can cross the BBB [203]. Thus whole body treatment for Duchenne is a realistic possibility, although it must be stated that distal $D M D$ mutations affecting the expression of Dp71 are rare and mutationspecific treatments may have limited benefit for Duchenne patients when taken as a whole.

In summary, Dp71 is a ubiquitous and functionally diverse protein implicated in the neuropathophysiology of DMD. Advances in our understanding of its role(s) in the CNS may also have wider implications such as for cancer, neurodegeneration and neurodevelopmental and neuropsychiatric disorders.

Funding Information Dr. Anthony is financially supported by the Higher Education Funding Council for England (HEFCE) at the University of Northampton.

Open Access This article is licensed under a Creative Commons Attribution 4.0 International License, which permits use, sharing, adaptation, distribution and reproduction in any medium or format, as long as you give appropriate credit to the original author(s) and the source, provide a link to the Creative Commons licence, and indicate if changes were made. The images or other third party material in this article are included in the article's Creative Commons licence, unless indicated otherwise in a credit line to the material. If material is not included in the article's Creative Commons licence and your intended use is not permitted by statutory regulation or exceeds the permitted use, you will need to obtain permission directly from the copyright holder. To view a copy of this licence, visit http://creativecommons.org/licenses/by/4.0/.

\section{References}

1. Abbs S, Tuffery-Giraud S, Bakker E et al (2010) Best practice guidelines on molecular diagnostics in Duchenne/Becker muscular dystrophies. Neuromuscul Disord 20:422-427. https://doi.org/ 10.1016/j.nmd.2010.04.005

2. Muntoni F, Torelli S, Ferlini A (2003) Dystrophin and mutations: one gene, several proteins, multiple phenotypes. Lancet Neurol 2: 731-740

3. Tadayoni R, Rendon A, Soria-Jasso LE, Cisneros B (2012) Dystrophin Dp71: the smallest but multifunctional product of the Duchenne muscular dystrophy gene. Mol Neurobiol 45:4360. https://doi.org/10.1007/s12035-011-8218-9

4. Lidov HG, Selig S, Kunkel LM (1995) Dp140: a novel 140 kDa CNS transcript from the dystrophin locus. Hum Mol Genet 4:329 335

5. Taylor PJ, Betts GA, Maroulis S et al (2010) Dystrophin gene mutation location and the risk of cognitive impairment in Duchenne muscular dystrophy. PLoS One 5:e8803. https://doi. org/10.1371/journal.pone.0008803

6. Daoud F, Angeard N, Demerre B et al (2009) Analysis of Dp71 contribution in the severity of mental retardation through comparison of Duchenne and Becker patients differing by mutation consequences on Dp71 expression. Hum Mol Genet 18:3779-3794. https://doi.org/10.1093/hmg/ddp320

7. Moizard MP, Billard C, Toutain A et al (1998) Are Dp71 and Dp140 brain dystrophin isoforms related to cognitive impairment in Duchenne muscular dystrophy? Am J Med Genet 80:32-41. 
https://doi.org/10.1002/(SICI)1096-8628(19981102)80:1<32:: AID-AJMG6>3.0.CO;2-Y

8. Moizard M-P, Toutain A, Fournier D et al (2000) Severe cognitive impairment in DMD: obvious clinical evidence for Dp71 isoform point mutations screening. Eur J Hum Genet 8:552-556. https:// doi.org/10.1038/sj.ejhg.5200488

9. Tuffery S, Lenk U, Roberts RG et al (1995) Protein truncation test: analysis of two novel point mutations at the carboxy-terminus of the human dystrophin gene associated with mental retardation. Hum Mutat 6:126-135. https://doi.org/10.1002/humu. 1380060205

10. Pane M, Lombardo ME, Alfieri P, et al (2012) Attention deficit hyperactivity disorder and cognitive function in Duchenne Muscular dystrophy: phenotype-genotype correlation. J Pediatr 161:705-709.e1. https://doi.org/10.1016/j.jpeds.2012.03.020

11. Lenk U, Hanke R, Thiele H, Speer A (1993) Point mutations at the carboxy terminus of the human dystrophin gene: implications for an association with mental retardation in DMD patients. Hum Mol Genet 2:1877-1881. https://doi.org/10.1093/hmg/2.11.1877

12. Doorenweerd N, Straathof CS, Dumas EM et al (2014) Reduced cerebral gray matter and altered white matter in boys with Duchenne muscular dystrophy. Ann Neurol 76:403-411. https:// doi.org/10.1002/ana.24222

13. Ricotti V, Mandy WPL, Scoto M et al (2016) Neurodevelopmental, emotional, and behavioural problems in Duchenne muscular dystrophy in relation to underlying dystrophin gene mutations. Dev Med Child Neurol 58:77-84. https:// doi.org/10.1111/dmen.12922

14. Cotton S, Voudouris NJ, Greenwood KM (2001) Intelligence and Duchenne muscular dystrophy: full-scale, verbal, and performance intelligence quotients. Dev Med Child Neurol 43:497-501

15. Milic Rasic V, Vojinovic D, Pesovic J et al (2014) Intellectual ability in the duchenne muscular dystrophy and dystrophin gene mutation location. Balkan J Med Genet 17:25-35. https://doi.org/ 10.2478/bjmg-2014-0071

16. Lee AJ, Buckingham ET, Kauer AJ, Mathews KD (2018) Descriptive phenotype of obsessive compulsive symptoms in males with Duchenne muscular dystrophy. J Child Neurol 33: 572-579. https://doi.org/10.1177/0883073818774439

17. Hendriksen RGF, Vles JSH, Aalbers MW et al (2018) Brainrelated comorbidities in boys and men with Duchenne muscular dystrophy: a descriptive study. Eur J Paediatr Neurol 22:488-497. https://doi.org/10.1016/j.ejpn.2017.12.004

18. Goodwin F, Muntoni F, Dubowitz V (1997) Epilepsy in Duchenne and Becker muscular dystrophies. Eur J Paediatr Neurol 1:115 119. https://doi.org/10.1016/S1090-3798(97)80042-6

19. Etemadifar M, Molaei S (2004) Epilepsy in boys with Duchenne muscular dystrophy. J Res Med Sci 9:116-119

20. Pane M, Messina S, Bruno C et al (2013) Duchenne muscular dystrophy and epilepsy. Neuromuscul Disord 23:313-315

21. Cyrulnik SE, Hinton VJ (2008) Duchenne muscular dystrophy: a cerebellar disorder? Neurosci Biobehav Rev 32:486-496. https:// doi.org/10.1016/j.neubiorev.2007.09.001

22. Fujino H, Saito T, Matsumura T et al (2018) Autism spectrum disorders are prevalent among patients with dystrophinopathies. Neurol Sci 39:1279-1282. https://doi.org/10.1007/s10072-0183341-2

23. Colombo P, Nobile M, Tesei A et al (2017) Assessing mental health in boys with Duchenne muscular dystrophy: emotional, behavioural and neurodevelopmental profile in an Italian clinical sample. Eur J Paediatr Neurol 21:639-647. https://doi.org/10. 1016/j.ejpn.2017.02.007

24. Conway KC, Mathews KD, Paramsothy P et al (2015) Neurobehavioral concerns among males with dystrophinopathy using population-based surveillance data from the muscular dystrophy surveillance, tracking, and research network. J Dev Behav
Pediatr 36:455-463. https://doi.org/10.1097/DBP. 0000000000000177

25. Pangalila RF, van den Bos GA, Bartels B et al (2015) Prevalence of fatigue, pain, and affective disorders in adults with Duchenne muscular dystrophy and their associations with quality of life. Arch Phys Med Rehabil 96:1242-1247. https://doi.org/10.1016/ j.apmr.2015.02.012

26. Latimer R, Street N, Conway KC et al (2017) Secondary conditions among males with Duchenne or becker muscular dystrophy. J Child Neurol 32:663-670. https://doi.org/10.1177/ 0883073817701368

27. Banihani R, Smile S, Yoon G et al (2015) Cognitive and neurobehavioral profile in boys with Duchenne muscular dystrophy. J Child Neurol 30:1472-1482. https://doi.org/10.1177/ 0883073815570154

28. Hendriksen JGM, Vles JSH (2008) Neuropsychiatric disorders in males with Duchenne muscular dystrophy: frequency rate of attention-deficit hyperactivity disorder (ADHD), autism spectrum disorder, and obsessive - compulsive disorder. J Child Neurol 23: 477-481. https://doi.org/10.1177/0883073807309775

29. Astrea G, Pecini C, Gasperini F et al (2015) Reading impairment in Duchenne muscular dystrophy: a pilot study to investigate similarities and differences with developmental dyslexia. Res Dev Disabil 45-46:168-177. https://doi.org/10.1016/J.RIDD.2015. 07.025

30. Billard C, Gillet P, Signoret JL et al (1992) Cognitive functions in Duchenne muscular dystrophy: a reappraisal and comparison with spinal muscular atrophy. Neuromuscul Disord 2:371-378

31. Hendriksen JGM, Vles JSH (2006) Are males with duchenne muscular dystrophy at risk for reading disabilities? https://doi. org/10.1016/j.pediatrneurol.2005.08.029

32. Dorman C, Hurley AD, D'Avignon J (1988) Language and learning disorders of older boys with Duchenne muscular dystrophy. Dev Med Child Neurol 30:316-327

33. Hinton VJ, De Vivo DC, Nereo NE et al (2001) Selective deficits in verbal working memory associated with a known genetic etiology: the neuropsychological profile of duchenne muscular dystrophy. J Int Neuropsychol Soc 7:45-54

34. Battini R, Chieffo D, Bulgheroni S et al (2018) Cognitive profile in Duchenne muscular dystrophy boys without intellectual disability: the role of executive functions. Neuromuscul Disord 28:122128. https://doi.org/10.1016/j.nmd.2017.11.018

35. Leaffer EB, Fee RJ, Hinton VJ (2016) Digit span performance in children with dystrophinopathy: a verbal span or working memory contribution? J Int Neuropsychol Soc 22:777-784. https://doi.org/ $10.1017 / \mathrm{S} 1355617716000461$

36. Ueda Y, Suwazono S, Maedo S, Higuchi I (2017) Profile of cognitive function in adults with Duchenne muscular dystrophy. Brain and Development 39:225-230. https://doi.org/10.1016/j.braindev. 2016.10.005

37. Hinton V, Fee RJ, Goldstein EM, De Vivo DC (2007) Verbal and memory skills in males with Duchenne muscular dystrophy. Dev Med Child Neurol 49:123-128. https://doi.org/10.1111/j.14698749.2007.00123.x

38. Hinton VJ, Nereo NE, Fee RJ, Cyrulnik SE (2006) Social behavior problems in boys with Duchenne muscular dystrophy. J Dev Behav Pediatr 27:470-476

39. Thangarajh M, Hendriksen J, McDermott MP et al (2019) Relationships between DMD mutations and neurodevelopment in dystrophinopathy. Neurology. https://doi.org/10.1212/WNL. 0000000000008363 , https://doi.org/10.1212/wnl. 0000000000008363

40. Billard C, Gillet P, Barthez M et al (1998) Reading ability and processing in Duchenne muscular dystrophy and spinal muscular atrophy. Dev Med Child Neurol 40:12-20 
41. Sicinski P, Geng Y, Ryder-Cook AS et al (1989) The molecular basis of muscular dystrophy in the mdx mouse: a point mutation. Science 244:1578-1580

42. Sekiguchi M, Zushida K, Yoshida M et al (2009) A deficit of brain dystrophin impairs specific amygdala GABAergic transmission and enhances defensive behaviour in mice. Brain 132:124-135. https://doi.org/10.1093/brain/awn253

43. Vaillend C, Chaussenot R (2017) Relationships linking emotional, motor, cognitive and GABAergic dysfunctions in dystrophindeficient $m d x$ mice. Hum Mol Genet 26:ddx013. https://doi.org/ 10.1093/hmg/ddx013

44. Miranda R, Nagapin F, Bozon B et al (2015) Altered social behavior and ultrasonic communication in the dystrophin-deficient mdx mouse model of Duchenne muscular dystrophy. Mol Autism 6:60. https://doi.org/10.1186/s13229-015-0053-9

45. Chaussenot R, Edeline J-M, Le Bec B et al (2015) Cognitive dysfunction in the dystrophin-deficient mouse model of Duchenne muscular dystrophy: a reappraisal from sensory to executive processes. Neurobiol Learn Mem 124:111-122. https:// doi.org/10.1016/j.nlm.2015.07.006

46. Muntoni F, Mateddu A, Serra G (1991) Passive avoidance behaviour deficit in the mdx mouse. Neuromuscul Disord 1:121-123

47. Vaillend C, Rendon A, Misslin R, Ungerer A (1995) Influence of dystrophin-gene mutation on $\mathrm{mdx}$ mouse behavior. I. Retention deficits at long delays in spontaneous alternation and bar-pressing tasks. Behav Genet 25:569-579

48. Vaillend C, Billard J-M, Laroche S (2004) Impaired long-term spatial and recognition memory and enhanced CA1 hippocampal LTP in the dystrophin-deficient Dmdmdx mouse. Neurobiol Dis 17:10-20. https://doi.org/10.1016/j.nbd.2004.05.004

49. Remmelink E, Aartsma-Rus A, Smit AB et al (2016) Cognitive flexibility deficits in a mouse model for the absence of full-length dystrophin. Genes Brain Behav 15:558-567. https://doi.org/10. 1111/gbb.12301

50. Vaillend C, Billard JM, Claudepierre T et al (1998) Spatial discrimination learning and CA1 hippocampal synaptic plasticity in $\mathrm{mdx}$ and $\mathrm{mdx} 3 \mathrm{cv}$ mice lacking dystrophin gene products. Neuroscience 86:53-66

51. Sesay AK, Errington ML, Levita L, Bliss TV (1996) Spatial learning and hippocampal long-term potentiation are not impaired in mdx mice. Neurosci Lett 211:207-210. https://doi.org/10.1016/ 0304-3940(96)12747-6

52. Cox GA, Phelps SF, Chapman VM, Chamberlain JS (1993) New $\mathrm{mdx}$ mutation disrupts expression of muscle and nonmuscle isoforms of dystrophin. Nat Genet 4:87-93. https://doi.org/10.1038/ ng0593-87

53. Im W, Phelps SF, Copen EH et al (1996) Differential expression of dystrophin isoforms in strains of $\mathrm{mdx}$ mice with different mutations. Hum Mol Genet 5:1149-1153. https://doi.org/10.1093/hmg/ 5.8.1149

54. Vaillend C, Ungerer A (1999) Behavioral characterization of mdx3cv mice deficient in C-terminal dystrophins. Neuromuscul Disord 9:296-304

55. Sarig R, Mezger-Lallemand V, Gitelman I et al (1999) Targeted inactivation of Dp71, the major non-muscle product of the DMD gene: differential activity of the Dp71 promoter during development. Hum Mol Genet 8:1-10

56. Helleringer R, Le Verger D, Li X, et al (2018) Cerebellar synapse properties and cerebellum-dependent motor and non-motor performance in Dp71 -null mice. Dis Model Mech 11:dmm033258. https://doi.org/10.1242/dmm.033258

57. Chaussenot R, Amar M, Fossier P, Vaillend C (2019) Dp71dystrophin deficiency alters prefrontal cortex excitationinhibition balance and executive functions. Mol Neurobiol 56: 2670-2684. https://doi.org/10.1007/s12035-018-1259-6
58. Daoud F, Candelario-Martínez A, Billard J-M et al (2009) Role of mental retardation-associated dystrophin-gene product dp71 in excitatory synapse organization, synaptic plasticity and behavioral functions. PLoS One 4:e6574. https://doi.org/10.1371/journal. pone. 0006574

59. Sánchez L, Beltrán E, De Stefani A et al (2018) Clinical and genetic characterisation of dystrophin-deficient muscular dystrophy in a family of miniature poodle dogs. PLoS One 13. https:// doi.org/10.1371/journal.pone.0193372

60. Dubowitz V, Crome L (1969) The central nervous system in Duchenne muscular dystrophy. Brain 92:805-808

61. Rae C, Scott RB, Thompson CH et al (1998) Brain biochemistry in Duchenne muscular dystrophy: a $1 \mathrm{H}$ magnetic resonance and neuropsychological study. J Neurol Sci 160:148-157

62. Bresolin N, Castelli E, Comi GP et al (1994) Cognitive impairment in Duchenne muscular dystrophy. Neuromuscul Disord 4: 359-369

63. Anderson JL, Head SI, Rae C, Morley JW (2002) Brain function in Duchenne muscular dystrophy. Brain 125:4-13. https://doi.org/ 10.1093/brain/awf012

64. Rosman NP, Kakulas BA (1966) Mental deficiency associated with muscular dystrophy. A neuropathological study. Brain 89: 769-788

65. Rosman NP (1970) The cerebral defect and myopathy in Duchenne muscular dystrophy. A comparative clinicopathological study. Neurology 20:329-335

66. Jagadha V, Becker LE (1988) Brain morphology in Duchenne muscular dystrophy: a Golgi study. Pediatr Neurol 4:87-92. https://doi.org/10.1016/0887-8994(88)90047-1

67. Itoh K, Jinnai K, Tada K et al (1999) Multifocal glial nodules in a case of Duchenne muscular dystrophy with severe mental retardation. Neuropathology 19:322-327. https://doi.org/10.1046/j.14401789.1999.00240.x

68. Yoshioka M, Okuno T, Honda Y, Nakano Y (1980) Central nervous system involvement in progressive muscular dystrophy. Arch Dis Child 55:589-594

69. Chen DH, Takeshima Y, Ishikawa Y et al (1999) A novel deletion of the dystrophin S-promoter region cosegregating with mental retardation. Neurology 52:638-640. https://doi.org/10.1212/ WNL.52.3.638

70. Appleton RE, Bushby K, Gardner-Medwin D et al (1991) Head circumference and intellectual performance of patients with Duchenne muscular dystrophy. Dev Med Child Neurol 33:884 890

71. Schmidt B, Watters GV, Rosenblatt B, Silver K (1985) Increased head circumference in patients with duchenne muscular dystrophy. Ann Neurol 17:620-621. https://doi.org/10.1002/ana. 410170622

72. Perneczky R, Wagenpfeil S, Lunetta KL et al (2010) Head circumference, atrophy, and cognition: implications for brain reserve in Alzheimer disease. Neurology 75:137-142. https://doi.org/10. 1212/WNL.0b013e3181e7ca97

73. Straathof CSM, Doorenweerd N, Wokke BHA et al (2014) Temporalis muscle hypertrophy and reduced skull eccentricity in duchenne muscular dystrophy. J Child Neurol 29:1344-1348. https://doi.org/10.1177/0883073813518106

74. Byron CD, Hamrick MW, Wingard CJ (2006) Alterations of temporalis muscle contractile force and histological content from the myostatin and Mdx deficient mouse. Arch Oral Biol 51:396405. https://doi.org/10.1016/j.archoralbio.2005.09.006

75. Kogelman B, Khmelinskii A, Verhaart I et al (2018) Influence of full-length dystrophin on brain volumes in mouse models of Duchenne muscular dystrophy. PLoS One 13:e0194636. https:// doi.org/10.1371/journal.pone.0194636

76. Di Lazzaro V, Restuccia D, Servidei S et al (1998) Functional involvement of cerebral cortex in duchenne muscular dystrophy. 
Muscle Nerve 21:662-664. https://doi.org/10.1002/(SICI)10974598(199805)21:5<662::AID-MUS18>3.0.CO;2-X

77. Lv SY, Zou QH, Cui JL et al (2011) Decreased gray matter concentration and local synchronization of spontaneous activity in the motor cortex in Duchenne muscular dystrophy. Am J Neuroradiol 32:2196-2200. https://doi.org/10.3174/ajnr.A2718

78. Goodnough CL, Gao Y, Li X et al (2014) Lack of dystrophin results in abnormal cerebral diffusion and perfusion in vivo. Neuroimage 102:809-816. https://doi.org/10.1016/J. NEUROIMAGE.2014.08.053

79. Miranda R, Sebrie C, Degrouard J et al (2009) Reorganization of inhibitory synapses and increased PSD length of perforated excitatory synapses in hippocampal area CA1 of dystrophin-deficient mdx mice. Cereb Cortex 19:876-888. https://doi.org/10.1093/ cercor/bhn135

80. Xu S, Shi D, Pratt SJP et al (2015) Abnormalities in brain structure and biochemistry associated with $\mathrm{mdx}$ mice measured by in vivo MRI and high resolution localized 1H MRS. Neuromuscul Disord 25:764-772. https://doi.org/10.1016/j.nmd.2015.07.003

81. Doorenweerd N, Mahfouz A, van Putten M et al (2017) Timing and localization of human dystrophin isoform expression provide insights into the cognitive phenotype of Duchenne muscular dystrophy. Sci Rep 7:12575. https://doi.org/10.1038/s41598-01712981-5

82. Lidov HGW, Byers TJ, Watkins SC, Kunkel LM (1990) Localization of dystrophin to postsynaptic regions of central nervous system cortical neurons. Nature 348:725-728. https://doi. org/10.1038/348725a0

83. Lidov HG (1996) Dystrophin in the nervous system. Brain Pathol 6:63-77

84. Nudel U, Zuk D, Einat P et al (1989) Duchenne muscular dystrophy gene product is not identical in muscle and brain. Nature 337: 76-78. https://doi.org/10.1038/337076a0

85. Lidov HG (2000) The molecular neuropathology of the muscular dystrophies: a review and update. J Neuropathol Exp Neurol 59: 1019-1030. https://doi.org/10.1093/jnen/59.12.1019

86. Holder E, Maeda M, Bies RD (1996) Expression and regulation of the dystrophin Purkinje promoter in human skeletal muscle, heart, and brain. Hum Genet 97:232-239. https://doi.org/10.1007/ BF02265272

87. Górecki DC, Monaco AP, Derry JM et al (1992) Expression of four alternative dystrophin transcripts in brain regions regulated by different promoters. Hum Mol Genet 1:505-510. https://doi. org $/ 10.1093 / \mathrm{hmg} / 1.7 .505$

88. D'Souza VN, Nguyen TM, Morris GE et al (1995) A novel dystrophin isoform is required for normal retinal electrophysiology. Hum Mol Genet 4:837-842. https://doi.org/10.1093/hmg/4.5.837

89. Byers TJ, Lidov HG, Kunkel LM (1993) An alternative dystrophin transcript specific to peripheral nerve. Nat Genet 4:77-81. https://doi.org/10.1038/ng0593-77

90. Lederfein D, Levy Z, Augier N et al (1992) A 71-kilodalton protein is a major product of the Duchenne muscular dystrophy gene in brain and other nonmuscle tissues. Proc Natl Acad Sci U S A 89:5346-5350. https://doi.org/10.1073/pnas.89.12.5346

91. Austin RC, Howard PL, D'Souza VN et al (1995) Cloning and characterization of alternatively spliced isoforms of Dp71. Hum Mol Genet 4:1475-1483. https://doi.org/10.1093/hmg/4.9.1475

92. Tinsley JM, Blake DJ, Davies KE (1993) Apo-dystrophin-3: a $2.2 \mathrm{~kb}$ transcript from the DMD locus encoding the dystrophin glycoprotein binding site. Hum Mol Genet 2:521-524. https:// doi.org/10.1093/hmg/2.5.521

93. Hinton VJ, De Vivo DC, Nereo NE et al (2000) Poor verbal working memory across intellectual level in boys with Duchenne dystrophy. Neurology 54:2127-2132

94. Desmond JE, Gabrieli JD, Wagner AD et al (1997) Lobular patterns of cerebellar activation in verbal working-memory and finger-tapping tasks as revealed by functional MRI. J Neurosci 17:9675-9685

95. Levisohn L, Cronin-Golomb A, Schmahmann JD (2000) Neuropsychological consequences of cerebellar tumour resection in children: cerebellar cognitive affective syndrome in a paediatric population. Brain 123(Pt 5):1041-1050

96. Stay TL, Miterko LN, Arancillo M et al (2019) In vivo cerebellar circuit function is disrupted in an $m d x$ mouse model of Duchenne muscular dystrophy. Dis Model Mech dmm 040840. https://doi. org/10.1242/dmm.040840

97. Sbriccoli A, Santarelli M, Carretta D et al (1995) Architectural changes of the cortico-spinal system in the dystrophin defective mdx mouse. Neurosci Lett 200:53-56

98. Miranda R, Laroche S, Vaillend C (2016) Reduced neuronal density in the CA1 anterodorsal hippocampus of the mdx mouse. Neuromuscul Disord 26:775-781. https://doi.org/10.1016/j.nmd. 2016.08.006

99. Knuesel I, Mastrocola M, Zuellig RA et al (1999) Short communication: altered synaptic clustering of GABAA receptors in mice lacking dystrophin (mdx mice). Eur J Neurosci 11:4457-4462

100. Miranda R, Nudel U, Laroche S, Vaillend C (2011) Altered presynaptic ultrastructure in excitatory hippocampal synapses of mice lacking dystrophins Dp427 or Dp71. Neurobiol Dis 43:134-141. https://doi.org/10.1016/j.nbd.2011.02.017

101. Culligan K, Glover L, Dowling P, Ohlendieck K (2001) Brain dystrophin-glycoprotein complex: persistent expression of betadystroglycan, impaired oligomerization of Dp71 and upregulation of utrophins in animal models of muscular dystrophy. BMC Cell Biol 2:2

102. Lee JS, Pfund Z, Juhász C et al (2002) Altered regional brain glucose metabolism in Duchenne muscular dystrophy: a pet study. Muscle Nerve 26:506-512. https://doi.org/10.1002/mus.10238

103. Rae C, Griffin JL, Blair DH et al (2002) Abnormalities in brain biochemistry associated with lack of dystrophin: studies of the mdx mouse. Neuromuscul Disord 12:121-129. https://doi.org/ 10.1016/S0960-8966(01)00253-X

104. Tracey I, Scott RB, Thompson CH, et al (1995) Brain abnormalities in Duchenne muscular dystrophy: phosphorus-31 magnetic resonance spectroscopy and neuropsychological study. Lancet (London, England) 345:1260-4

105. Tracey I, Dunn JF, Radda GK (1996) Brain metabolism is abnormal in the mdx model of Duchenne muscular dystrophy. Brain 119(Pt 3):1039-1044

106. Misuri G, Lanini B, Gigliotti F et al (2000) Mechanism of CO2 retention in patients with neuromuscular disease. Chest 117:447453. https://doi.org/10.1378/chest.117.2.447

107. Doorenweerd N, Hooijmans M, Schubert SA et al (2017) Proton magnetic resonance spectroscopy indicates preserved cerebral biochemical composition in Duchenne muscular dystrophy patients. J Neuromuscul Dis 4:53-58. https://doi.org/10.3233/JND-160201

108. Kato T, Nishina M, Matsushita K et al (1997) Increased cerebral choline-compounds in Duchenne muscular dystrophy. Neuroreport 8:1435-1437

109. Frigeri A, Nicchia GP, Nico B et al (2001) Aquaporin-4 deficiency in skeletal muscle and brain of dystrophic mdx mice. FASEB J 15: 90-98. https://doi.org/10.1096/fj.00-0260com

110. Nico B, Paola Nicchia G, Frigeri A et al (2004) Altered bloodbrain barrier development in dystrophic MDX mice. Neuroscience 125:921-935. https://doi.org/10.1016/j.neuroscience.2004.02.008

111. Annese T, Corsi P, Ruggieri S et al (2016) Isolation and characterization of neural stem cells from dystrophic mdx mouse. Exp Cell Res 343:190-207. https://doi.org/10.1016/j.yexcr.2016.03.019

112. Jancsik V, Hajós F (1999) The demonstration of immunoreactive dystrophin and its developmental expression in perivascular astrocytes. Brain Res 831:200-205. https://doi.org/10.1016/s00068993(99)01445-6 
113. Mehler MF, Haas KZ, Kessler JA, Stanton PK (1992) Enhanced sensitivity of hippocampal pyramidal neurons from mdx mice to hypoxia-induced loss of synaptic transmission. Proc Natl Acad Sci U S A 89:2461-2465. https://doi.org/10.1073/PNAS.89.6.2461

114. Vaillend C, Billard J-M (2002) Facilitated CA1 hippocampal synaptic plasticity in dystrophin-deficient mice: Role for GABAA receptors? Hippocampus 12:713-717. https://doi.org/10.1002/ hipo. 10068

115. Vaillend C, Ungerer A, Billard J-M (1999) Facilitated NMDA receptor-mediated synaptic plasticity in the hippocampal CA1 area of dystrophin-deficient mice. Synapse 33:59-70. https://doi.org/ 10.1002/(SICI)1098-2396(199907)33:1<59::AID-SYN6>3.0. $\mathrm{CO} ; 2-\mathrm{K}$

116. Hugnot JP, Gilgenkrantz H, Vincent N et al (1992) Distal transcript of the dystrophin gene initiated from an alternative first exon and encoding a $75-\mathrm{kDa}$ protein widely distributed in nonmuscle tissues. Proc Natl Acad Sci U S A 89:7506. https://doi.org/10.1073/ PNAS.89.16.7506

117. Blake DJ, Love DR, Tinsley J et al (1992) Characterization of a $4.8 \mathrm{~kb}$ transcript from the Duchenne muscular dystrophy locus expressed in Schwannoma cells. Hum Mol Genet 1:103-109. https://doi.org/10.1093/hmg/1.2.103

118. Bar S, Barnea E, Levy Z et al (1990) A novel product of the Duchenne muscular dystrophy gene which greatly differs from the known isoforms in its structure and tissue distribution. Biochem J 272:557-560. https://doi.org/10.1042/bj2720557

119. Kawaguchi T, Niba E, Rani A et al (2018) Detection of dystrophin Dp71 in human skeletal muscle using an automated capillary Western assay system. Int J Mol Sci 19:1546. https://doi.org/10. 3390/ijms 19061546

120. Rapaport D, Lederfein D, den Dunnen JT et al (1992) Characterization and cell type distribution of a novel, major transcript of the Duchenne muscular dystrophy gene. Differentiation 49:187-193. https://doi.org/10.1111/j.1432-0436.1992.tb00666. $\mathrm{x}$

121. Howard PL, Klamut HJ, Ray PN (1998) Identification of a novel actin binding site within the Dp71 dystrophin isoform. FEBS Lett 441:337-341. https://doi.org/10.1016/S0014-5793(98)01566-X

122. Lederfein D, Yaffe D, Nudel U (1993) A housekeeping type promoter, located in the 3' region of the Duchenne muscular dystrophy gene, controls the expression of $\mathrm{Dp} 71$, a major product of the gene. Hum Mol Genet 2:1883-1888. https://doi.org/10.1093/hmg/ 2.11.1883

123. Leibovitz S, Meshorer A, Fridman Y et al (2002) Exogenous Dp71 is a dominant negative competitor of dystrophin in skeletal muscle. Neuromuscul Disord 12:836-844

124. Morales-Lázaro SL, González-Ramírez R, Gómez P et al (2010) Induction of dystrophin Dp71 expression during neuronal differentiation: opposite roles of Sp1 and AP2 $\alpha$ in Dp71 promoter activity. J Neurochem 112:474-485. https://doi.org/10.1111/j.14714159.2009.06467.x

125. Imamura M, Ozawa E (1998) Differential expression of dystrophin isoforms and utrophin during dibutyryl-cAMP-induced morphological differentiation of rat brain astrocytes. Proc Natl Acad Sci U S A 95:6139-6144. https://doi.org/10.1073/pnas.95.11. 6139

126. Cisneros B, Rendon A, Genty V et al (1996) Expression of dystrophin Dp71 during PC12 cell differentiation. Neurosci Lett 213: 107-110. https://doi.org/10.1016/0304-3940(96)12863-9

127. Marquez FG, Cisneros B, Garcia F et al (2003) Differential expression and subcellular distribution of dystrophin Dp71 isoforms during differentiation process. Neuroscience 118:957-966. https:// doi.org/10.1016/s0306-4522(03)00063-0

128. Fujimoto T, Yaoi T, Fushiki S, Itoh K (2017) Dp71 is regulated by phosphorylation and ubiquitin-proteasome system in neuronal cells. Biochem Biophys Res Commun 492:349-355. https://doi. org/10.1016/J.BBRC.2017.08.108

129. Feener CA, Koenig M, Kunkel LM (1989) Alternative splicing of human dystrophin mRNA generates isoforms at the carboxy terminus. Nature 338:509-511. https://doi.org/10.1038/338509a0

130. Ceccarini M, Rizzo G, Rosa G et al (1997) A splice variant of Dp71 lacking the syntrophin binding site is expressed in early stages of human neural development. Dev Brain Res 103:77-82. https://doi.org/10.1016/S0165-3806(97)00122-3

131. Austin RC, Morris GE, Howard PL et al (2000) Expression and synthesis of alternatively spliced variants of Dp71 in adult human brain. Neuromuscul Disord 10:187-193. https://doi.org/10.1016/ S0960-8966(99)00105-4

132. Saint Martín A, Aragón J, Depardon-Benítez F et al (2012) Identification of Dp71e, a new dystrophin with a novel carboxyterminal end. FEBS J 279:66-77. https://doi.org/10.1111/j.17424658.2011.08399.x

133. Aragón J, Martínez-Herrera A, Romo-Yáñez J et al (2016) Identification of Dp71 isoforms expressed in PC12 cells: subcellular localization and colocalization with $\beta$-dystroglycan and $\alpha 1$ syntrophin. J Mol Neurosci 58:201-209. https://doi.org/10.1007/ s12031-015-0657-8

134. Rani AQM, Farea M, Maeta K et al (2019) Identification of the shortest splice variant of Dp71, together with five known variants, in glioblastoma cells. Biochem Biophys Res Commun 508:640 645. https://doi.org/10.1016/j.bbrc.2018.11.168

135. Aragón J, González-Reyes M, Romo-Yáñez J et al (2018) Dystrophin Dp71 isoforms are differentially expressed in the mouse brain and retina: report of new alternative splicing and a novel nomenclature for Dp71 isoforms. Mol Neurobiol 55:13761386. https://doi.org/10.1007/s12035-017-0405-x

136. Fabbrizio E, Nudelqt U, Hugon G, et al (1994) Characterization and localization of a $77 \mathrm{kDa}$ protein related to the dystrophin gene family

137. Connors NC, Adams ME, Froehner SC, Kofuji P (2004) The potassium channel Kir4.1 associates with the dystrophinglycoprotein complex via $\alpha$-syntrophin in glia. J Biol Chem 279:28387-28392. https://doi.org/10.1074/jbc.M402604200

138. Perronnet C, Vaillend C (2010) Dystrophins, utrophins, and associated scaffolding complexes: role in mammalian brain and implications for therapeutic strategies. J Biomed Biotechnol 2010:1-19. https://doi.org/10.1155/2010/849426

139. Fort PE, Sene A, Pannicke T et al (2008) Kir4.1 and AQP4 associate with Dp71- and utrophin-DAPs complexes in specific and defined microdomains of Müller retinal glial cell membrane. Glia 56:597-610. https://doi.org/10.1002/glia.20633

140. Dalloz C, Sarig R, Fort P et al (2003) Targeted inactivation of dystrophin gene product Dp71: phenotypic impact in mouse retina. Hum Mol Genet 12:1543-1554. https://doi.org/10.1093/hmg/ $\operatorname{ddg} 170$

141. Jung D, Yang B, Meyer J et al (1995) Identification and characterization of the dystrophin anchoring site on beta-dystroglycan. $\mathrm{J}$ Biol Chem 270:27305-27310. https://doi.org/10.1074/jbc.270.45. 27305

142. Yang B, Jung D, Rafael JA et al (1995) Identification of $\alpha$ syntrophin binding to syntrophin triplet, dystrophin, and utrophin. J Biol Chem 270:4975-4978. https://doi.org/10.1074/JBC.270. 10.4975

143. Blake DJ, Hawkes R, Benson MA, Beesley PW (1999) Different dystrophin-like complexes are expressed in neurons and glia. $\mathrm{J}$ Cell Biol 147:645-658. https://doi.org/10.1083/jcb.147.3.645

144. Haenggi T, Soontornmalai A, Schaub MC, Fritschy JM (2004) The role of utrophin and Dp71 for assembly of different dystrophin-associated protein complexes (DPCs) in the choroid plexus and microvasculature of the brain. Neuroscience 129: 403-413. https://doi.org/10.1016/j.neuroscience.2004.06.079 
145. Claudepierre T, Dalloz C, Mornet D et al (2000) Characterization of the intermolecular associations of the dystrophin-associated glycoprotein complex in retinal Müller glial cells. J Cell Sci 113(Pt 19):3409-3417

146. Romo-Yáñez J, Ceja V, Ilarraza-Lomelí R et al (2007) Dp71ab/ DAPs complex composition changes during the differentiation process in PC12 cells. J Cell Biochem 102:82-97. https://doi. org $/ 10.1002 / j \mathrm{cb} .21281$

147. Acosta R, Montañez C, Fuentes-Mera L et al (2004) Dystrophin Dp71 is required for neurite outgrowth in PC12 cells. Exp Cell Res 296:265-275. https://doi.org/10.1016/j.yexcr.2004.01.015

148. García-Cruz C, Merino-Jiménez C, Ceja V et al (2019) The dystrophin isoform Dp71e $\Delta 71$ is involved in neurite outgrowth and neuronal differentiation of PC12 cells. J Proteome 191:80-87. https://doi.org/10.1016/j.jprot.2018.03.027

149. Herrera-Salazar A, García-Villegas R, Aragón J et al (2016) Overexpression of mutant dystrophin Dp71[INCREMENT]7879 stimulates cell proliferation. Neuroreport 27:6-11. https://doi. org/10.1097/WNR.0000000000000475

150. Aragón J, Romo-Yáñez J, Martínez-Herrera A et al (2011) Characterization of Dp71 $\Delta 78-79$, a novel dystrophin mutant that stimulates PC12 cell differentiation. J Neurochem 119:697-707. https://doi.org/10.1111/j.1471-4159.2011.07347.x

151. Merino-Jiménez C, Aragón J, Ceja V et al (2016) Dp71 ${ }_{78-79}$ dystrophin mutant stimulates neurite outgrowth in PC12 cells via upregulation and phosphorylation of HspB1. Proteomics 16: 1331-1340. https://doi.org/10.1002/pmic.201500211

152. Aleman V, Osorio B, Chavez O et al (2001) Subcellular localization of Dp71 dystrophin isoforms in cultured hippocampal neurons and forebrain astrocytes. Histochem Cell Biol 115:243-254

153. Nishida A, Yasuno S, Takeuchi A et al (2016) HEK293 cells express dystrophin Dp71 with nucleus-specific localization of Dp71ab. Histochem Cell Biol 146:301-309. https://doi.org/10. 1007/s00418-016-1439-2

154. González E, Montañez C, Ray PN et al (2000) Alternative splicing regulates the nuclear or cytoplasmic localization of dystrophin Dp71. FEBS Lett 482:209-214

155. Calderilla-Barbosa L, Ortega A, Cisneros B (2006) Phosphorylation of dystrophin Dp71d by $\mathrm{Ca} 2+/$ calmodulin-dependent protein kinase II modulates the Dp71d nuclear localization in PC12 cells. J Neurochem 98:713-722. https://doi.org/10. 1111/j.1471-4159.2006.03904.x

156. Rosa G, Ceccarini M, Cavaldesi M et al (1996) Localization of the dystrophin binding site at the carboxyl terminus of $\beta$-dystroglycan. Biochem Biophys Res Commun 223:272-277. https://doi. org/10.1006/bbrc.1996.0883

157. Villarreal-Silva M, Suárez-Sánchez R, Rodríguez-Muñoz R et al (2010) Dystrophin Dp71 is critical for stability of the DAPs in the nucleus of PC12 cells. Neurochem Res 35:366-373. https://doi. org/10.1007/s11064-009-0064-z

158. Fuentes-Mera L, Rodríguez-Muñoz R, González-Ramírez R et al (2006) Characterization of a novel Dp71 dystrophin-associated protein complex (DAPC) present in the nucleus of HeLa cells: members of the nuclear DAPC associate with the nuclear matrix. Exp Cell Res 312:3023-3035. https://doi.org/10.1016/j.yexcr. 2006.06.002

159. González-Ramírez R, Morales-Lázaro SL, Tapia-Ramírez V et al (2008) Nuclear and nuclear envelope localization of dystrophin Dp71 and dystrophin-associated proteins (DAPs) in the C2C12 muscle cells: DAPs nuclear localization is modulated during myogenesis. J Cell Biochem 105:735-745. https://doi.org/10. $1002 /$ jcb. 21870

160. Lara-Chacón B, De León MB, Leocadio D et al (2010) Characterization of an importin in $\alpha / \beta$-recognized nuclear localization signal in $\beta$-dystroglycan. J Cell Biochem 110:706-717. https://doi.org/10.1002/jcb.22581
161. Suárez-Sánchez R, Aguilar A, Wagstaff KM et al (2014) Nucleocytoplasmic shuttling of the Duchenne muscular dystrophy gene product dystrophin Dp71d is dependent on the importin $\alpha / \beta$ and CRM1 nuclear transporters and microtubule motor $d y-$ nein. Biochim Biophys Acta, Mol Cell Res 1843:985-1001. https://doi.org/10.1016/j.bbamcr.2014.01.027

162. Chávez O, Harricane MC, Alemán V et al (2000) Mitochondrial expression of a short dystrophin-like product with molecular weight of $71 \mathrm{kDa}$. Biochem Biophys Res Commun 274:275280. https://doi.org/10.1006/bbrc.2000.3118

163. García-Tovar CG, Luna J, Mena R et al (2002) Dystrophin isoform Dp71 is present in lamellipodia and focal complexes in human astrocytoma cells U-373 MG. Acta Histochem 104:245-254

164. Austin RC, Fox JEB, Werstuck GH et al (2002) Identification of Dp71 isoforms in the platelet membrane cytoskeleton. Potential role in thrombin-mediated platelet adhesion. J Biol Chem 277: 47106-47113. https://doi.org/10.1074/jbc.M203289200

165. Arturo Enríquez-Aragón J, Cerna-Cortés J, Bermúdez De León M, et al (2005) Dystrophin Dp71 in PC12 cell adhesion

166. Cerna J, Cerecedo D, Ortega A et al (2006) Dystrophin Dp71f associates with the $\beta 1$-integrin adhesion complex to modulate PC12 cell adhesion. J Mol Biol 362:954-965. https://doi.org/10. 1016/j.jmb.2006.07.075

167. Villarreal-Silva M, Centeno-Cruz F, Suárez-Sánchez R et al (2011) Knockdown of dystrophin Dp71 impairs PC12 cells cycle: localization in the spindle and cytokinesis structures implies a role for Dp71 in cell division. PLoS One 6:e23504. https://doi.org/10. 1371/journal.pone.0023504

168. Martin LT, Glass M, Dosunmu E, Martin PT (2007) Altered expression of natively glycosylated $\alpha$ dystroglycan in pediatric solid tumors. Hum Pathol 38:1657-1668. https://doi.org/10.1016/j. humpath.2007.03.025

169. Higginson JR, Thompson O, Winder SJ (2008) Targeting of dystroglycan to the cleavage furrow and midbody in cytokinesis. Int $\mathrm{J}$ Biochem Cell Biol 40:892-900. https://doi.org/10.1016/j.biocel. 2007.10.019

170. Ash A, Machado L, Raleigh SM, Anthony K (2018) Neuropathophysiology of Duchenne muscular dystrophy: involvement of the dystrophin isoform Dp71 in cell migration and proliferation. Neuromuscul Disord 28:S13-S14. https://doi. org/10.1016/S0960-8966(18)30328-6

171. Tan SS, Zhao S, Chen Z et al (2017) Altered biological properties in Dp71 Over-expressing HBE cells. Cell Physiol Biochem 43: 2022-2036. https://doi.org/10.1159/000484181

172. Suárez-Sánchez R, Cisneros B (2016) Dystrophin Dp71, a novel tumor suppressor? J Xiangya Med 1:13-13. https://doi.org/10. 21037/jxym.2016.12.13

173. Rodríguez-Muñoz R, Villarreal-Silva M, González-Ramírez R et al (2008) Neuronal differentiation modulates the dystrophin Dp71d binding to the nuclear matrix. Biochem Biophys Res Commun 375:303-307. https://doi.org/10.1016/j.bbrc.2008.07. 135

174. Tan S, Zhao S, Xiao X et al (2019) Dp71 depleted HBE cells displayed increased DNA damage and apoptosis induced by H2O2. Cell Mol Biol Lett 24:42. https://doi.org/10.1186/s11658019-0169-6

175. Perronnet $\mathrm{C}$, Chagneau $\mathrm{C}$, Le Blanc $\mathrm{P}$ et al (2012) Upregulation of brain utrophin does not rescue behavioral alterations in dystrophin-deficient mice. Hum Mol Genet 21:2263-2276. https://doi.org/10.1093/hmg/dds047

176. Anthony K, Cirak S, Torelli S et al (2011) Dystrophin quantification and clinical correlations in Becker muscular dystrophy: implications for clinical trials. Brain 134:3547-3559. https://doi.org/ 10.1093/brain/awr291

177. Anthony K, Arechavala-Gomeza V, Ricotti V et al (2014) Biochemical characterization of patients with in-frame or out-of- 
frame DMD deletions pertinent to exon 44 or 45 skipping. JAMA Neurol 71:32-40. https://doi.org/10.1001/jamaneurol.2013.4908

178. Bushby KMD, Appleton R, Anderson LVB et al (1995) Deletion status and intellectual impairment in Duchenne muscular dystrophy. Dev Med Child Neurol 37:260-269. https://doi.org/10.1111/ j.1469-8749.1995.tb12000.x

179. Hodgson SV, Abbs S, Clark S et al (1992) Correlation of clinical and deletion data in Duchenne and Becker muscular dystrophy, with special reference to mental ability. Neuromuscul Disord 2: 269-276. https://doi.org/10.1016/0960-8966(92)90059-F

180. Lenk U, Oexle K, Voit T et al (1996) A cysteine 3340 substitution in the dystroglycan-binding domain of dystrophin associated with Duchenne muscular dystrophy, mental retardation and absence of the ERG b-wave. Hum Mol Genet 5:973-975. https://doi.org/10. 1093/hmg/5.7.973

181. Cau M, Cao A, Loi D et al (1998) Two novel mutations (10410 $\mathrm{T} \rightarrow \mathrm{G} ; 10296 \mathrm{del} \mathrm{C}$ ) at carboxy-terminus of the dystrophin gene associated with mental retardation. Hum Mutat 12:70-70. https:// doi.org/10.1002/(SICI) 1098-1004(1998)12:1<70::AIDHUMU13>3.0.CO;2-G

182. Melis MA, Muntoni F, Cau M et al (1998) Novel nonsense mutation $(\mathrm{C} \rightarrow \mathrm{A}$ nt 10512) in exon 72 of dystrophin gene leading to exon skipping in a patient with a mild dystrophinopathy. Hum Mutat 11:S137-S138. https://doi.org/10.1002/humu.1380110146

183. Desguerre I, Christov C, Mayer M et al (2009) Clinical heterogeneity of Duchenne muscular dystrophy (DMD): definition of subphenotypes and predictive criteria by long-term follow-up. PLoS One 4. https://doi.org/10.1371/journal.pone.0004347

184. Nico B, Tamma R, Annese T, et al (2010) Glial dystrophinassociated proteins, laminin and agrin, are downregulated in the brain of mdx mouse. 90:1645-1660. https://doi.org/10.1038/ labinvest.2010.149

185. Vaillend C, Poirier R, Laroche S (2008) Genes, plasticity and mental retardation. Behav Brain Res 192:88-105

186. Granger R, Staubli U, Davis M et al (1993) A drug that facilitates glutamatergic transmission reduces exploratory activity and improves performance in a learning-dependent task. Synapse 15: 326-329. https://doi.org/10.1002/syn.890150409

187. Piga D, Salani S, Magri F et al (2019) Human induced pluripotent stem cell models for the study and treatment of Duchenne and Becker muscular dystrophies. Ther Adv Neurol Disord 12: 1756286419833478. https://doi.org/10.1177/1756286419833478

188. Patel AM, Wierda K, Thorrez L et al (2019) Dystrophin deficiency leads to dysfunctional glutamate clearance in iPSC derived astrocytes. Transl Psychiatry 9:200. https://doi.org/10.1038/s41398019-0535-1

189. Ruggieri S, Viggiano L, Annese Tet al (2019) DP71 and SERCA2 alteration in human neurons of a Duchenne muscular dystrophy patient. Stem Cell Res Ther 10:29. https://doi.org/10.1186/ s13287-018-1125-5

190. Britzolaki A, Saurine J, Flaherty E et al (2018) The SERCA2: a gatekeeper of neuronal calcium homeostasis in the brain. Cell Mol Neurobiol 38:981-994. https://doi.org/10.1007/s10571-0180583-8
191. Lopez JR, Kolster J, Uryash A et al (2018) Dysregulation of intracellular $\mathrm{Ca} 2+$ in dystrophic cortical and hippocampal neurons. Mol Neurobiol 55:603-618. https://doi.org/10.1007/s12035-0160311-7

192. Reiner O, Karzbrun E, Kshirsagar A, Kaibuchi K (2016) Regulation of neuronal migration, an emerging topic in autism spectrum disorders. J Neurochem 136:440-456. https://doi.org/ 10.1111/jnc. 13403

193. Graus-Porta D, Blaess S, Senften M et al (2001) Beta1-class integrins regulate the development of laminae and folia in the cerebral and cerebellar cortex. Neuron 31:367-379

194. Niks EH, Doorenweerd N, Hooijmans MT et al (2017) Proton magnetic resonance spectroscopy indicates preserved cerebral biochemical composition in Duchenne muscular dystrophy patients. Eur J Paediatr Neurol 21:e227. https://doi.org/10.1016/j.ejpn. 2017.04.1238

195. Bellot-Saez A, Kékesi O, Morley JW, Buskila Y (2017) Astrocytic modulation of neuronal excitability through $\mathrm{K}+$ spatial buffering. Neurosci Biobehav Rev 77:87-97. https://doi.org/10.1016/j. neubiorev.2017.03.002

196. Hendriksen RGF, Hoogland G, Schipper S et al (2015) A possible role of dystrophin in neuronal excitability: a review of the current literature. Neurosci Biobehav Rev 51:255-262. https://doi.org/10. 1016/j.neubiorev.2015.01.023

197. Eide PK, Hansson H-A (2018) Astrogliosis and impaired aquaporin-4 and dystrophin systems in idiopathic normal pressure hydrocephalus. Neuropathol Appl Neurobiol 44:474-490. https:// doi.org/10.1111/nan.12420

198. Alfano LN, Charleston JS, Connolly AM et al (2019) Long-term treatment with eteplirsen in nonambulatory patients with Duchenne muscular dystrophy. Medicine (Baltimore) 98:e15858. https://doi.org/10.1097/md.0000000000015858

199. Ebrahimi-Fakhari D, Dillmann U, Flotats-Bastardas M et al (2018) Off-label use of Ataluren in four non-ambulatory patients with nonsense mutation Duchenne muscular dystrophy: effects on cardiac and pulmonary function and muscle strength. Front Pediatr 6 . https://doi.org/10.3389/fped.2018.00316

200. Anthony K, Gallo J-M (2010) Aberrant RNA processing events in neurological disorders. Brain Res 1338:67-77. https://doi.org/10. 1016/j.brainres.2010.03.008

201. Vaillend C, Zarrouki F, Vacca O (2019) Gene therapy for central nervous system in Duchenne muscular dystrophy. Muscle Gene Therapy. Springer International Publishing, In, pp. 417-438

202. Dallérac G, Perronnet C, Chagneau C et al (2011) Rescue of a dystrophin-like protein by exon skipping normalizes synaptic plasticity in the hippocampus of the mdx mouse. Neurobiol Dis 43:635-641. https://doi.org/10.1016/j.nbd.2011.05.012

203. Goyenvalle A, Leumann C, Garcia L (2016) Therapeutic potential of tricyclo-DNA antisense oligonucleotides. J Neuromuscul Dis 3: $157-167$

Publisher's Note Springer Nature remains neutral with regard to jurisdictional claims in published maps and institutional affiliations. 